\title{
The role of biotic factors during plant establishment in novel communities assessed with an agent-based simulation model
}

\author{
Janina Radny ${ }^{1}$, Katrin M. Meyer ${ }^{\text {Corresp. } 1}$ \\ ${ }^{1}$ Department of Ecosystem Modelling, Georg-August-Universität Göttingen, Göttingen, Germany \\ Corresponding Author: Katrin M. Meyer \\ Email address: Katrin.Meyer@forst.uni-goettingen.de
}

Background. Establishment success of non-native species is not only influenced by environmental conditions, but also by interactions with local competitors and enemies. The magnitude of these biotic interactions is mediated by species traits that reflect competitive strength or defence mechanisms. Our aim was to investigate the importance of species traits for successful establishment of non-native species in a native community exhibiting biotic resistance in the form of competition and herbivory.

Methods. We developed a trait-based individual-based simulation model tracking the survival of nonnative plants in a native community. In the model, non-native plants are characterized by high or low values of competition and defence traits. Model scenarios included variation of initial number of nonnatives, intensity of competitive interaction, density of herbivores and density as well as mixture of the native community.

Results. Traits related to competition had a much greater impact on survival of non-native species than traits related to defence. Survival rates of strong competitors never fell below $50 \%$ while survival of weak competitors averaged at about $10 \%$. Weak competitors were also much more susceptible to competitive pressures such as community density, composition and competition intensity. Strong competitors responded negatively to changes in competition intensity, but hardly to composition or density of the native community. High initial numbers of non-native individuals decreased survival rate of strong competitors, but increased the survival rate of weak competitors. Survival under herbivore attack was only slightly higher for plants with high defensive ability than for those with low defensive ability. Surprisingly though, herbivory increased survival of species classified as weak competitors.

Discussion. High survival rates of strong non-native competitors relate to a higher probability of successful establishment than for weak competitors. However, the reduced survival of strong competitors at high initial numbers indicates a self-thinning effect, probably mediated by a strongly competitive milieu. For weak competitors, our model emphasizes positive effects of high propagule pressure known from field studies. General effects of herbivory or defence abilities on survival were not supported by our model. However, the positive effect of herbivory on survival of weak competitors indicated side effects of herbivory, such as weakening resident competitors. This might play an important role for establishment of non-natives in a new community. 
1 The role of biotic factors during plant establishment in novel communities

5 'Department of Ecosystem Modelling, Georg-August Universität Göttingen, Göttingen, Germany

6 Corresponding Author: K.M. Meyer, email: kmeyer5@uni-goettingen.de assessed with an agent-based simulation model

Janina Radny ${ }^{1}$, Katrin M. Meyer ${ }^{1}$

\section{Abstract}

Background. Establishment success of non-native species is not only influenced by environmental conditions, but also by interactions with local competitors and enemies. The magnitude of these biotic interactions is mediated by species traits that reflect competitive strength or defence mechanisms. Our aim was to investigate the importance of species traits for successful establishment of non-native species in a native community exhibiting biotic resistance in the form of competition and herbivory.

Methods. We developed a trait-based individual-based simulation model tracking the survival of non-native plants in a native community. In the model, non-native plants are characterized by high or low values of competition and defence traits. Model scenarios included variation of initial number of non-natives, intensity of competitive interaction, density of herbivores and density as well as mixture of the native community.

Results. Traits related to competition had a much greater impact on survival of non-native species than traits related to defence. Survival rates of strong competitors never fell below $50 \%$ while survival of weak competitors averaged at about $10 \%$. Weak competitors were also much more susceptible to competitive pressures such as community density, composition and competition intensity. Strong competitors responded negatively to changes in competition intensity, but hardly to composition or density of the native community. High initial numbers of non-native individuals decreased survival rate of strong competitors, but increased the survival rate of weak competitors. 
27 Survival under herbivore attack was only slightly higher for plants with high defensive ability than 28 for those with low defensive ability. Surprisingly though, herbivory increased survival of species classified as weak competitors.

Discussion. High survival rates of strong non-native competitors relate to a higher probability of successful establishment than for weak competitors. However, the reduced survival of strong competitors at high initial numbers indicates a self-thinning effect, probably mediated by a strongly competitive milieu. For weak competitors, our model emphasizes positive effects of high propagule pressure known from field studies. General effects of herbivory or defence abilities on survival were not supported by our model. However, the positive effect of herbivory on survival of weak competitors indicated side effects of herbivory, such as weakening resident competitors. This might play an important role for establishment of non-natives in a new community.

\section{Introduction}

In response to current climate change, range borders and distribution patterns of many species have shifted along with changes in environmental conditions (Chen et al., 2011; Maggini et al., 2011; Parmesan and Yohe, 2003; Walther et al., 2002). The abiotic and biotic environment in novel habitats plays an important role for capturing and eventually predicting range shift dynamics of species (Berg et al., 2010). On a large scale range shifts are correlated with bioclimatic and environmental factors and whether a plant species is able to reach a novel habitat. Thus, range expansion of a species is a continuous process, acting on a large-scale landscape. However, realization of range expansion is determined by a series of successful local establishment events of individuals (Bakkenes et al., 2002), that build up viable populations in the novel habitat (Figure 1). Local establishment success strongly depends on biotic interactions with the resident community. Such interactions include for example competition with resident plants or herbivore attack (Levine et al., 2004). In fact, diverging trends in speed, extent and directions of species range shifts may be not only an expression of their ability to reach a novel habitat, but also to persist in novel communities (Lenoir et al., 2010; Maggini et al., 2011). These local negative processes can add up and might eventually prevent further range shifts. Thus, although a species range is typically described on large, often continental scales, it is limited by small-scale processes 
56 at the borders of the range. This is in line with the claim to consider dispersal and local 57 establishment success of species and individuals in order to gain insights on range dynamics 58 (Guisan and Thuiller, 2005; Pearson and Dawson, 2003; Wisz et al., 2013). In a novel habitat, the 59 non-native species will face novel interactions with the resident community. The magnitude of the 60 effect of these interactions is partially determined by the ability of the novel species to respond to the biotic pressures (Kempel et al., 2013; Roux et al., 2012; Wisz et al., 2013). This ability is mediated by plant traits. Despite the general acknowledgement of the importance of traits and biotic pressures for establishment success, the interaction of these factors is not well studied in the context of range expansion.

We constructed an individual-based simulation model to scrutinize how these factors together affect success or failure of plant establishment in a novel community. Field surveys are generally incapable of capturing failed invasion attempts (Zenni and Nunez, 2013), but modelling allows for comprehensive systematic modifications and full control of the setup. Data from a preceding greenhouse experiment (Radny et al., in press) were used as a basis for model construction and parametrization (see 2.2. parametrization).

Early establishment of populations in novel habitats in a local context is an essential first step in range shift dynamics of a species. Therefore, in this model we focus on such biotic interactions that operate on local scales and with immediate contact between the interacting entities. These biotic interactions are enemy attack and competition for resources between neighbouring plants.

Biotic pressures such as competition and enemy attack may hamper establishment success of a novel species in a community by decreasing individual fitness. The causes are obvious: when mutually contested resources are captured by competing species, the inferior competitor can use less of the contested resource for its own growth and reproduction. Eventually, it may die when resource uptake falls below a metabolic threshold (Lin et al., 2012; Schmitz, 2000). Enemy attack can strongly weaken a plant through damage of plant tissue or organs and even result in lethal consumption. Loss of tissue may pose an additive negative effect on plants under competition (Heard and Sax, 2013; Kim et al., 2013; Kuijper et al., 2004). In fact, invasion biology studies have often pointed out that very effectively expanding, i.e. invasive, non-native species suffer less from enemy attack than native or non-invasive non-native species (Cappuccino and Carpenter, 2005; Engelkes et al., 2008; Matter et al., 2012; but see Heard and Sax, 2013). This effect, referred 
86

to as enemy release, is one line of argument to explain invasiveness of non-native plant species in intercontinental invasions (Joshi and Vrieling, 2005; Keane and Crawley, 2002). Since lately enemy release is also studied in intracontinental range shifts, motivated by long-distance dispersal of plant species (Engelkes et al., 2008; Harvey et al., 2010; Nehrbass et al., 2007).

Traits of species mediate interactions and are often used to describe community composition in classical community ecology (McGill et al., 2006). Intercontinental invasion biology relies on certain traits that are shared by successful invaders to inform risk assessments. However, the trait set of the "perfect invader" yet remains to be found (Speek et al., 2011). Further, it is largely unclear how strongly trait sets vary under different interaction regimes. For our model, we use the framework of biotic resistance composed of resource competition and herbivore attack (Levine et al., 2004). We describe novel species by a set of traits to respond to these components of biotic resistance. Our central model aim is to assess how non-native species with different trait profiles can establish in a novel community despite negative biotic interactions.

The traits used in the model reflect the ability of a plant to a) compete with neighbours and b) defend against enemies. Based on size-symmetric competition models (Connolly and Wayne, 1996; Damgaard and Weiner, 2008), we use seed mass as a measure of plant size and as the trait representing competitive ability (Metz et al., 1992). Other traits have also been associated with competitive strength (Goldberg, 1996), but plant size is a straightforward measure (Domingos, 1999), which is well supported (Aikio, 2004; Weiner and Damgaard, 2006). Mechanical barriers and toxins belong to the traits a plant can use to prevent herbivore attack, and often plants build up a complex defence syndrome of multiple traits (Agrawal and Fishbein, 2006). For our purpose, the form of defence mechanism is not of interest. Thus, we implemented the defence mechanism as the stochastic ability of enemy repulsion.

In summary, the aim of the model presented here is to systematically investigate how local establishment success of non-native species is influenced by biotic resistance of the native community, by competition and defence traits of non-natives, and by the interaction of biotic resistance and traits. We present a comprehensive analysis of the consequences of a broad range of parameters representing biotic resistance and species traits for non-native species survival and thus local establishment. 


\section{Materials \& Methods}

\section{Model description}

118 Our model description follows the ODD protocol (Grimm et al., 2010, 2006). Model structure is 119 partly based on (Lin et al., 2012).

1. Purpose

121

122

123

124

125

126

127

128

129

130

131

132

133

134

\section{Entities, state variables, and scales}

We implemented two general types of agents, plants and herbivores. Plants are non-mobile agents, characterized by their $\mathrm{x}-\mathrm{y}$-position and values related to growth, reproduction and defence (Table 1 and 2). On initialization, the plants are represented as seeds and hatch in the first step. We distinguish two general types of plants, native and non-native, and twelve species, of which four are native and eight are non-native. Parameters have been retrieved from a preceding experiment (Radny et al. in press) and from the literature (see section Model parametrization and validation).

The simulated world comprises of a homogenous 100 x 100 cell grid. Each grid cell represents 1 $\mathrm{cm}^{2}$, thus we model a $1 \times 1 \mathrm{~m}$ plot. To avoid edge effects, the world is a torus, i.e. opposing edges are connected (Grimm and Railsback, 2005).

Each time step is representing one day. A simulation comprises 76 days, i.e. the average lifespan of a non-native species in the preceding experiment. The simulation was aborted earlier if no nonnative individuals were left on the grid. 
142 During each time step, the simulation routine is exerted in the following order: herbivores appear 143 and feed on random plants, competition intensity is calculated for each plant individual, plants 144 grow according to this competition intensity and plants age. After 76 days, the plants produce and 145 disperse seeds and die. Dead plants are removed from the grid. The process schedule is visualized 146 in Figure 2.

We follow the assumption that community composition can at least partly be related to biotic interactions and that biotic interactions are closely connected to functional traits of species (McGill et al., 2006). We apply a basic profile of functional traits related to the ability of species to a) compete with neighbours and $b$ ) defend against enemies. We also address biotic resistance, i.e. negative impacts of resident herbivores and competitors on non-native plants, which can influence local establishment success (Kempel et al., 2013).

5. Emergence

156

157

158

Several patterns related to individual plant development and population dynamics emerge from the model. Examples include spatial patterns of plant individuals, population dynamics of nonnative and native plants, reproductive output, and plant size distributions. For the purpose of this paper, we focus on initial and final number of individuals of non-native species per time step as a basis for deriving survival rate in the establishment phase (see section Scenario analysis).

6. Interactions

We explicitly model competitive interactions between neighbouring plants via the Zone-OfInfluence (ZOI) approach (Lin et al., 2012; Weiner and Damgaard, 2006). Furthermore, herbivores interact with plants by consuming parts of the aboveground biomass of the encountered plants. 
168

Plant individuals are initialized with random x-y-coordinates. To reflect individual deviance from population mean values, initial biomass of plants is calculated as seed mass multiplied by a random number, drawn from a normal distribution with a mean of 1 and a standard deviation of 0.1 . Instead of defining fixed relative growth rates (rgr), plants determine their own growth rate through

\section{ln(maximum biomass) - In(initial biomass)) / maximum age}

(Eq 1)

(Hunt, 1982). This approach propagates the stochasticity involved in initial biomasses to the distribution of relative growth rates. Daily density of herbivores is stochastic, as grasshopper density is multiplied with a stochastic number of meals per herbivore (see Submodels: Herbivory). Success of each foraging attempt of herbivores on a given plant is stochastic, based on the repulsion value of the plant.

\section{Initialization}

Each simulation run starts with placement of seeds on the grid at random xy-positions. Initial native community population size is based on plant densities in the preceding greenhouse experiment (Radny et al. in press). In that experiment, planting pots of $18 \times 18 \mathrm{~cm}$ carried either 12 or 44 native individuals, i.e. 300 or 1100 individuals per $\mathrm{m}^{2}$. Mixtures of native species are based on either the experiment or approximated literature values (Table 2) depending on the simulation scenario (Table 3). For experiment-based mixtures, each native species is represented with the same number of individuals, called "even mixture" hereafter. For literature values, we use the reported seed bank size of the respective species as initial numbers (Table 2), called "seedbank mixture" hereafter. Per simulation scenario, there is one non-native species mixed into the native community. Different simulation scenarios were run with initially 8, 16, 32, 64, 128 and 256 seeds of nonnative species. These scenarios reflect different levels of introduction efforts or proximity to core range with higher population densities (Kolar and Lodge, 2001). 
The model does not require any input data beyond the model parameters.

Herbivore agents are created at the beginning of each time step (Figure 2). The grasshopper Locusta migratoria is used as herbivore model species due to its wide distribution (CABI, 2013) and generalist feeding behaviour (Macel et al., 2005; Schmitz and Booth, 1997). We had also chosen this species as herbivore in the preceding experiment (Radny et al. in press). Herbivore density is varied based on literature values and density in the experiment, ranging from 3.2 grasshoppers per $\mathrm{m}^{2}$ (literature value Ledergerber et al., 1997) to 75 grasshoppers per $\mathrm{m}^{2}$ (experimental value, based on Morriën et al., 2011). One scenario is implemented without herbivores (Table 3). Here, neither native nor non-native species experience herbivory. Consumption does not happen all at once, but in 7 to 10 meals of about $7.5 \mathrm{mg}$ each. In a natural setting, it is not likely that a highly mobile insect is feeding on the same plant individual all day. Thus, we implemented in-between meal movement. To reduce computing effort, we created one dummy herbivore individual per meal. The number of dummy herbivore individuals that represent one herbivore was determined by multiplying each herbivore by a random number drawn from the interval $[7,10]$. This may, for instance, lead to eight dummy herbivore individuals representing eight meals of herbivore $\mathrm{x}$ plus ten dummy herbivore individuals representing ten meals of herbivore y and so forth. The movement of the dummy herbivore individuals reflects in-between meal movement of the original herbivores. This simplification is justified, because we are not interested in the fate of individual herbivores, but just their effect on plant biomass. This multiplication allows us to model a process which is operating at a finer temporal scale than the global time step (one day).

220 Each dummy herbivore is initialized at random $\mathrm{x}-\mathrm{y}$-coordinates and approaches a random plant in a radius of 50 patches. To consume the approached plant, a random number drawn from the interval 
$222[0,1]$ must be greater than the repulsion value of the respective plant. A high repulsion value thus

223 represents high defence of a plant, e.g. through physical barriers or toxins. If dummy herbivores

224 are not successful with foraging, they leave that meal out and are removed from the grid. This

225 procedure still adequately represents the overall effect of herbivory on plants. All successful

226 dummy herbivores are removed directly after foraging. Thereby, herbivore density fluctuates

227 daily. As we observed in our greenhouse experiment (Radny et al. in press), a plant dies in the

228 model if more than $90 \%$ of its current biomass is consumed by herbivores, and it is removed from

229 the grid.

Plant competition and growth

232

233

234

235

236

237

238

239

240

241

242

243

244

245

246

Plants interact competitively with their neighbours. To model competition, we follow the ZoneOf-Influence approach (Berger et al., 2008; Lin et al., 2012; Weiner et al., 2001; Weiner and Damgaard, 2006). The ZOI of a plant is represented by a circular area $A_{Z O I}$ with radius $r$. Based on Lin et al. (2012), radius $r_{i}$ is allometrically related to biomass $B$ of plant $i$ at time $t$ :

$$
r_{i}=B_{i}(t)^{3 / 8} * \sqrt{\frac{1}{\pi}}
$$

(Eq 2)

Note that $B(t)$ is determined after herbivore attack. Based on Lin et al. (2012), plant growth in the next time step is determined by the relative plant growth rate $\mathrm{rgr}$, the area of the ZOI $A_{Z O I}$, current biomass $B$ and maximum biomass $B_{\max }$ :

$$
\frac{d B}{d t}=r g r * A_{Z o i} *\left(1-\left(\frac{B}{B_{\max }}\right)^{1 / 4}\right)
$$

\section{(Eq 3)}

In most cases, the ZOI of a plant covers several grid cells. Thus, $A_{Z O I}$ consists of the sum of the area of the grid cells $c$ that are occupied. Equation 3 applies when a plant is growing without neighbours, i.e. none of the cells within $A_{Z O I}$ is occupied by another but the focal plant. When two or more plants are neighbours, i.e. their ZOIs overlap in at least one cell, plant $i$ calculates its 
247 effective area $A_{\text {eff, } i}$ as the sum of the area of the grid cells $c$ it occupies, each weighted by the 248 proportion of its current biomass $B_{i}(t)$ relative to the total biomass of all overlapping plant 249 individuals $j$ to $k$ in this grid cell, modified by the degree of asymmetry of competition $\Theta$ (Lin et 250 al., 2012; Weiner and Damgaard, 2006):

$$
A_{e f f, i}(t)=\sum_{c_{i}} \frac{B_{i}(t)^{\Theta}}{\sum_{j}^{k} B_{j}(t)^{\Theta}} d c
$$

252

253

254

255

256

\section{(Eq 4)}

where $d c$ is the area of the respective grid cell c. In our case, all grid cells have the same area. Thus, instead of using $d c$ as in equation 4 , the summed area of the grid cells of the ZOI of plant $i$ can be rearranged and expressed in terms of the biomass of plant $i$ (Lin et al., 2012):

$$
A_{e f f, i}(t)=B_{i}(t)^{3 / 4} \sum_{c_{i}} \frac{B_{i}(t)^{\Theta}}{\sum_{j}^{k} B_{j}(t)^{\Theta}}
$$

\section{$257 \quad($ Eq 5)}

258 We use the degree of asymmetry as a measure of competition intensity. Intensity of competition 259 determines how the contested resources at any patch are shared among the competing plants, 260 depending on their biomass relative to the other competitors. With $\Theta=0$, resources are shared 261 equally among plants regardless of their biomass. Increasing $\Theta$ leads to an increasing weight of 262 biomass for capturing contested resources in a shared cell. With $\Theta=1$, a larger plant receives a 263 larger share of the contested resources than a smaller plant, proportional to its biomass (perfect 264 size-symmetry).

265 Mathematically, $\Theta$ can be located between 0 and $\infty$ (Schwinning and Weiner, 1998), but for our 266 purpose, we use $\Theta=0,0.5$ and 1 in different model runs.

267 Plant growth under competition is implemented following Lin et al. (2012) as: 


$$
\frac{d B}{d t}=r g r * A_{e f f} *\left(1-\left(\frac{B}{B_{\max }}\right)^{1 / 4}\right)
$$

271 The difference between Eq. 3 and Eq. 6 is that either all resources within the zones of influence 272 are considered to calculate growth regardless of neighbouring competitors $\left(A_{z o i}\right)$, or that only the 273 share of resources captured after competition with neighbours are considered to calculate growth $274\left(A_{e f f}\right)$.

275 If growth and resource uptake fall below the threshold of 0.05 of $B^{3 / 4}$, the plant cannot serve its 276 metabolic costs and dies (Lin et al., 2012; Schmitz, 2000). Overall, plant growth is strongly 277 determined by plant biomass in our model (Figure S1).

When plants reach maturity, i.e. maximum age, they produce seeds as a function of their final biomass. So under strong competition, final biomass does not necessarily match maximum biomass. In our greenhouse experiment (Radny et al. in press), we obtained a positive correlation between aboveground biomass and seed mass, i.e. total mass of all seeds produced per plant. We use this empirical correlation to determine seed mass per plant in the model, i.e. a ratio of $0.41 \mathrm{mg}$ seed mass per $\mathrm{mg}$ shoot biomass for strong competitors and $0.65 \mathrm{mg}$ seed mass per $\mathrm{mg}$ shoot biomass for weak competitors. The number of seeds per plant is implemented in the model as seed mass produced by the respective plant divided by average weight of a single seed (Table 2). We included stochastic variation of number of seeds of $+/-10 \%$. To reduce computational ballast, the number of seeds produced is reduced by winter mortality, including seed predation, and germination probability is applied. Thus, only seeds that survive winter and germinate in the next year are explicitly created. Seeds are then dispersed in a random angle with dispersal distance following a Weibull distribution to allow for long-distance dispersal (Colbach and Sache, 2001; Paradis et al., 2002). Number of seeds remaining on or being dispersed beyond the parental patch is recorded together with dispersal distance of each seed for future scaling-up of the model. 
297 Model parameters were partly derived from literature and partly from a preceding greenhouse

298

299

300

301

302

303

304

305

306

307

308

309

310

311

312

313

314

315

316

317

318

319

320

321

322

experiment (Radny et al., in press). The greenhouse experiment was conducted at the NIOOKNAW in Wageningen, The Netherlands. There, we planted microcosms of 18 x $18 \mathrm{~cm}$ with a native community of four plant species mixed with one non-native species per microcosm. The non-native species in the experiment differed in life-history traits related to competitive and defensive strength. In a fully crossed design, non-native species were exposed to two densities of natives to create different intensities of competitive pressures. Low density microcosms were planted with 12 individuals of native species and 4 individuals of one non-native species. High density microcosms were planted with 44 individuals of the native species and 4 individuals of one non-native species. Half of the microcosms were exposed to herbivory by two generalist herbivore species, Locusta migratoria (L.) and Mamestra brassicae (L.). We harvested the microcosms when non-native individuals had finished their seed production and recorded dry aboveground biomass, seed mass, and other performance parameters (Radny et al., in press),

For parameterization of non-native species in the model, we used data on the Mediterranean grass species Stipa capensis (Thunb.) and Bromus fasciculatus (C.Presl) from our experiment and from the literature (Table 1). The model differentiates between four trait profiles of generic non-native species: strong versus weak competitors combined with strong versus weak defenders.

Competitive strength is represented by average seed weight of $S$. capensis for strong competitors and B. fasciculatus for weak competitors (Table 1). Maximum biomass was assigned as a value relative to the native community (Table 2). Additionally, we derived the fitness measure biomassseed mass ratio from the preceding experiment by dividing total seed mass by total aboveground biomass of a species. This ratio was different for strong and weak competitors in the experiment and thus serves as another distinctive index for competitive strength (Table 1).

Defensive strength was modelled as repulsion of herbivores reflecting the chance of a plant to avoid herbivore attack. Repulsion values were derived from the percentage of individuals without or less $(>5 \%)$ clearly visible leaf damage of all individuals of a species that were exposed to 
323 herbivory during the preceding experiment. Values for strong defenders were obtained from $B$.

324 fasciculatus, whereas values for weak defenders were obtained from S. capensis (Table 1).

325 The parameterization of the native community in the model is based on the species in the 326 experimental native community, i.e. Agrostis capillaris (L.), Festuca rubra (L.), Hypericum 327 perforatum (L.) and Plantago lanceolata (L.). These four species are fairly widespread over 328 Europe (Roscher et al., 2004), and thus range-expanding plants from southern latitudes are likely 329 to encounter these species as interaction partners. With the exception of repulsion of herbivores 330 which was based on the overall observations of high and low attacks in the preceding experiment, 331 parameters used in the model for native species were based on literature data (Table 2).

332 In terms of validation of our model, no independent data were available for direct comparison with 333 model outputs. Therefore, we discussed comparisons of model outputs with the results of our 334 preceding experiment and conducted a scenario analysis (Table 3) and a sensitivity analysis to systematically explore the parameter space to explain as much output variation as possible.

Scenario analysis

338

339

340

341

342

343

344

345

346

347

348

The major goal of our simulation model was to investigate the local establishment of non-native species in a novel community, based on different trait configurations. To assess local establishment, we determined final population size, i.e. the number of reproducing adults at the end of a simulation run. To account for scenario-based differences in initial population sizes, we calculated survival rate as the ratio of final and initial numbers of non-native species. Model scenarios include the four different trait profiles (high and low competitive and defensive strength), six levels of initial population size of non-natives, three levels of competition intensity, two levels of community density, two levels of mixture of the native community, and three levels of herbivore density (Table 3, Figure 3). The competition index $\Theta$ describes the degree of intensity or asymmetry in competition and takes the values $0,0.5$ and 1 in our model. For the factor mixture of native community, native individuals are either mixed evenly or the percentage of native individuals of a species is derived from literature values about seedbank sizes (for more detail, see section Initialization). To reach our overall goal, we applied a binomial generalized linear model of the form 
352 Survival of non-natives $\sim$ competitive strength of non-natives + defensive strength of non-native 353 species + initial population size of non-natives + competition index $\Theta+$ native species density + 354 mixture of native species + herbivore density + all two-way interactions.

355 To account for overdispersion, we used a quasibinomial model. We simplified the generalized

356 linear model by removing non-significant terms $(p>=0.05)$ one by one, starting with the 357 interactions, until only significant terms were left in the model. If a non-significant main term was 358 part of at least one significant interaction term, we kept the main term in the model. This procedure 359 led to the removal of the interactions between native species density and mixture of native species, 360 defensive strength of non-natives and mixture of native species, and competitive and defensive 361 strength of non-native species. We used a chi-squared test to establish that the residual deviance 362 was significantly reduced compared to the residual deviance of the null model. We used the 363 software R version 3.3.3 (R Development Core Team, 2017) for data analysis.

Sensitivity analysis

366

367

368

369

370

371

372

373

374

375

376

377

378

379

380

We conducted a sensitivity analysis to assess the relative importance of the input parameters with respect to model output. To this end, we used the same combinations of parameter values as in the Scenario analysis (Table 3) except for the parameters mixture of the native community and trait profile of the non-native species. Instead of these parameters, we ran sensitivity simulations with only one native species and one non-native species each, which were called species 1 and species 2. This approach made it possible to systematically assess the full range of possible trait values and not just the fixed trait profiles used for native and non-native species in the scenario analysis. The tested traits were seed weight, maximum biomass, repulsion of herbivores, seed mass per shoot mass, and germination probability for species 1 and species 2 . To save computing time and still cover as much trait parameter space as possible, we applied Latin Hypercube Sampling (McKay et al., 1979) to assemble the trait profiles for the sensitivity analysis. We drew 15 samples from uniform distributions in the cases of repulsion (between 0 and 1) and germination probability (between 0.002 and 0.9) and from log2-distributions in the cases of seed weight (between 0.06 and 6), maximum biomass (between 3000 and 30000), and seed mass per shoot mass (between 0.02 and 6). The sampling distributions and ranges were determined based on our experience with the 
381 model simulations and always captured the range of the standard model parameterization. The

382 values for each trait were randomly rearranged and then assembled into 15 trait profiles for species

3831 and 15 trait profiles for species 2. Simulations were conducted with the full factorial combination

384 of the remaining parameters from the scenario analysis (Table 3) for each of the 15 combinations

385 of trait profiles of species 1 and 2. Model output was survival of species 2. The results of the

386 simulations were analysed with a generalized linear model with quasibinomial errors in the same

387 way as in the scenario analysis. This included model simplification and checking. To assess the

388 sensitivity of the model output to the input parameters, standardized model coefficients were

389 calculated by dividing model estimates by their standard errors. The absolute values of the

390 standardized model coefficients were divided by their sum to obtain sensitivity values between 0

391 and 1. Sensitivities were sorted and plotted for comparability.

\section{Results}

394

395

396

397

398

399

400

401

402

403

404

405

406

407

408

All main and interaction terms in the generalized linear model contributed significantly to survival of non-native species $(\mathrm{p}<0.01)$ except for mixture of native species (Table 4). The importance of competitive strength was very dominant and was a much stronger source of variation than defensive ability for survival of non-natives (main effects Comp and Def in Table 4, Figure 4). Overall, weak competitors had a much lower survival rate than strong competitors. Although the populations of weak non-native competitors had an increased chance of persistence with an increasing initial population size they were not able to catch up with survival rates of strong competitors (interaction Comp:initNN in Table 4, Figure 5). This was the case even though the survival of strong competitors was significantly negatively influenced by the population size of non-natives (interaction Comp:initNN in Table 4, Figure 5).

Intensity of competition $\Theta$ had a marked negative effect on survival rates of non-native plants, especially on weak competitors (main effect Theta and interaction Comp:Theta in Table 4, Figure 6). For weak competitors, average survival dropped by $80 \%$ when comparing equal share $(\Theta=0)$ and perfect size-symmetry $(\Theta=1)$. The decrease in survival rate was more severe in the even community mixture, as well as under high community density (interactions Comp:Mix and 
409 Comp:DensComm in Table 4, Figure 6). Strong competitors were neither visibly affected by 410 community mixture nor by increased population densities (Figure 6).

411 In our model runs, we found that herbivores were only able to kill a plant in very early stages when 412 they were very small. Herbivore damage increased survival of weaker competitors by a factor of 413 up to 1.5 (main effect DensHerb in Table 4, Figure 7). Weak competitors were also usually smaller 414 than strong competitors. For strong competitors, this effect was the other way round, i.e. presence 415 of herbivores was on average lowering the mean survival rate (interaction Comp:DensHerb in 416 Table 4, Figure 8). However, for strong competitors the decrease in survival rate was almost 417 intractable, lowering survival by only $4 \%$ under complete size symmetry. Strongly defended 418 species with $70 \%$ probability of repulsion only had a minor advantage in survival over weakly 419 defended species with $40 \%$ probability of repulsion (main effect Def in Table 4).

The sensitivity analysis showed that the model output survival of species 2 was most sensitive to the interaction between competition index $\Theta$ and seed weight, then to maximum biomass, the interaction between the seed weights of the two competing species, the interaction between seed weight and germination probability of the same species, and the interaction of seed weight of species 1 with maximum biomass of species 2 (Figure 8). Germination probability and seed weight were the next most important inputs for determining survival of species 2, together with the interaction between seed weight and repulsion of herbivores, competition index $\Theta$, and repulsion of herbivores. Overall, species traits and their interactions dominated the sensitivity ranking, whereas scenario parameters such as herbivore density, initial population size of non-natives and native species density were less important. Only the competition index $\Theta$ had a large, mostly indirect influence on survival of species 2 via interactions with species traits. In contrast to biomass- and competition-related parameters, herbivory-related parameters such as herbivore density and repulsion of herbivores played relatively minor roles for survival of species 2 .

\section{Discussion}

435 With our model, we investigated the establishment success of different types of generic non-native 436 plant species in a resident native community. We targeted three aspects that might influence 437 establishment success: trait profile of the non-native species, biotic pressures of the resident 
438 community, and the interactions between traits and pressures. The sensitivity analysis showed that

439 model outputs were much more sensitive to species traits and interactions between species traits 440 and biotic pressures than to biotic pressures alone. Thus, care should be taken in the choice of 441 experimental and model species and the traits they represent.

442 Competitive pressures and competitive traits exerted a much stronger influence on establishment 443 success than pressures and traits related to herbivory. This was supported by scenario analysis and 444 sensitivity analysis. Strong competitive traits were negatively correlated with initial density of non-natives in their effect on survival rates while a low initial number of non-natives with strong competitive ability resulted in high survival. We expect this might be due to a potential release effect from competition. These scenarios may for instance reflect distant satellite populations or the very edge of the expansion front, because there is evidence that population density on the range borders can be lower than in the core range (Brown, 1984; Maggini et al., 2011). High survival in these conditions may translate to an effective range shift, and this is more likely if long distance dispersal is included. However, a higher initial number led to a decrease of survival rate for strong competitors. An explanation may be that the high density of individuals with strong competitive traits led to a milieu of competitive stress, provoking intra-specific self-thinning effects (Morris, 2003). In our model setting, there was no evidence of complete extinction of non-native species due to competitive stress. Thus, the high intra-specific competition decreased individual survival, but did not decrease establishment success of the populations. It would thus probably not strongly impede range expansion of non-native species. Rather, this may contribute to stabilizing the range expansion.

Populations of weak competitive plants showed much lower survival at lower densities than strong competitors, implying a much lower chance of long-term establishment. Survival of weak competitors required very high initial numbers to exceed survival at low initial numbers of individuals in the population. This might be due to the sheer mass of non-native individuals that competed with the native community. In the most extreme setting 256 non-native individuals faced 300 native competitors. Thus, even if native species were the stronger competitors, a high number of weak non-native competitors might be able to overcome the biotic resistance, a trend that has already been observed in studies of intercontinental invasions (Lockwood et al., 2005; Simberloff, 467 2009). This effect was clearly observable although there was only a small difference between seed 
468 weight of weak non-native species and native competitors. We expect the effect to be even more 469 pronounced if the difference in seed weight was larger.

470 The advantage of strong competitors compared to weak competitors persisted in community 471 settings with more intense community-borne competitive stress, i.e. at higher community density 472 and species mixtures with a higher proportion of strong competitors. Higher community density 473 results obviously in a higher number of competitors for each individual plant and thus in most 474 cases a lower amount of resources that can be captured by any plant. For the community mixture, 475 an even number of individuals of all species led to a community with a much larger proportion of 476 strong competitors, i.e. P. lanceolata, the largest native species in our setting, than in the seed 477 bank-based mixture. However, since strong non-native competitors were characterized by twice 478 the seed weight of $P$. lanceolata they were probably not massively impacted by numbers of 479 competitors or community mixture. We observed this effect in the preceding empirical experiment 480 481 as well, where strong non-native competitors were massively dominating the native community (Radny et al. in press).

482 483

These results indicate that a range shift should be more effective for such plants that are strong competitors relative to species of the receiving community, provided that their seeds can reach a novel habitat. For intercontinental invasions competitive strength is one of the major explanations of invasive success (Vilà and Weiner, 2004). In the context of climate-change induced range expansion, this might become just as important or even more important, because changes in the microclimatic regime of habitats beyond current range borders may weaken the currently strong resident competitors and thus increase invasibility of communities (Alexander et al., 2016; Bauer, 2012; Stanton-Geddes et al., 2012).

However, the very low survival rates of weak competitors in our model may overestimate the negative impact of community competition on weak competitors in reality. For instance, in our preceding experiment (Radny et al. in press), drop-out rate of weak competitors was almost zero while in the model weak competitors responded very drastically to increased competitive pressure from the community in form of increased density, mixture and intensity of competitive asymmetry $(\Theta)$. Probably, in our model, we underestimated the abilities of weak competitors to avoid or tolerate competitive pressure from other species. This might be partly due to the implementation of competition with the Zone-of-influence approach. For theoretical models of competition 
498 between plant individuals, the Zone-of-Influence approach has been used many times at different 499 degrees of complexity (e.g. Berger et al., 2008; Lin et al., 2012; Weiner and Damgaard, 2006). 500 Despite several simplifications, it is a straightforward and comparatively easy method to 501 investigate competition (Berger et al., 2008). However, most of these models address 502 monocultures of species and thus implement the same type of interaction, i.e. degree of asymmetry $503 \Theta$, for all individuals. Interspecific interactions may be different though from intraspecific 504 interactions due to many different mechanisms. This may not only imply differences in 505 interspecific and intraspecific $\Theta$, but also different $\Theta$-values depending on the identity of the focal 506 species (Connolly and Wayne, 1996). Such mechanisms include for example allelopathy (Bais et 507 al., 2003) or adaption to the competitive disadvantage, e.g. development of shade tolerance in trees 508 (Dislich et al, 2010). Additionally, following the parsimony principle we have not yet considered 509 facilitative interactions in this model, although there are potentially strong impacts of facilitative 510 interactions in plant communities (e.g. Lin et al., 2012). Of course, parameterizing different 511 competition types for all possible interaction partners in our five-species system would require a 512 lot of data, which were not available in our case, and has also been attempted in only very few 513 comparable cases thus far.

514 Thus, we strongly advocate for the extension of multispecies models to incorporate different forms 515 of neighbourhood interactions not only as negative (competition) or positive (facilitation) 516 interactions, but also accounting for different intensities of inter- and intraspecific interactions. 517 This approach will require enhanced efforts in the collection of adequate data for parametrization, 518 but we expect a much better understanding of multispecies systems from such approaches 519 (Svenning et al 2014).

520 The effect of herbivory was comparatively small in our model. Accordingly, defensive strength 521 did not play an important role for survival. This may be due to the indirect influence of biomass 522 on survival via its effect on plant growth (Figure S1) combined with the fact that model herbivores 523 only consumed absolute amounts of biomass. This means that large plants suffered relatively less 524 from herbivory than small plants. In extra simulations, where herbivores consumed relative 525 amounts of plant biomass, defence traits were much more important for survival than in the 526 standard simulations (Supplemental Material S1). Herbivory has been reported to influence range 527 expansion and invasions, i.e. in spatial pattern and speed (Fagan et al., 2005; Herrero et al., 2016), 
528 yet it is unlikely that herbivory may entirely block establishment of novel species (Jeschke et al., 529 2012; Levine et al., 2004). However, although herbivory as a single factor may not pose a hard 530 barrier to establishment, studies found herbivory to be an important interacting effect under 531 competition through altering the competitive impact of individuals (Huang et al., 2012; Kim et al., 532 2013; Kuijper et al., 2004). Our model results support such an interaction between herbivory and 533 competition, where weak competitors showed increased survival under herbivory, especially with 534 higher densities of herbivores. We suspect that weak competitors benefited from being small 535 relative to their neighbours - either due to initial small size or due to cumulated negative effects 536 on biomass gain from competition. As sharing of the contested resource can depend on the relative 537 biomass of the competitors, loss of biomass due to herbivory can reduce the resource capture of 538 strong competitors, so that more resources are left to neighbouring weak competitors than in 539 scenarios without herbivory. In our model, the minimum amount of resource uptake for 540 maintenance of metabolism and thus survival is directly related to current biomass of the individual 541 (Brown et al., 2004). Thus, even a relatively small increase in resource capture can increase 542 survival of smaller plants.

543 Of course, our model did not capture the full complexity of possible herbivore impacts on plant 544 distribution and range expansion. Body size of herbivores and timing of herbivory have been 545 shown to differentially affect plant biodiversity (Kim et al., 2013; Olff and Ritchie, 1998), as well 546 as presence or absence of specialist herbivores (Joshi and Vrieling, 2005; Lakeman-Fraser and 547 Ewers, 2013). Our extra simulations on relative herbivory (Supplemental Material S1) indicate 548 that it may be worthwhile to explore a greater range and resolution of herbivory implementations 549 once the respective data become available for parameterization. Future model extensions could 550 reflect these factors as well as plant internal mechanisms such as compensatory growth (Lu and 551 Ding, 2012) and increase of defence mechanisms (Strauss and Agrawal, 1999). However, even 552 with our simple model design, we found a significant effect of herbivory - although not the 553 expected global decrease of survival, but an indirect effect through harming the competitors. This 554 indicates that herbivory effects may sometimes be overseen when they are not turning out as 555 expected and that this might also be a reason for contradicting results of similar studies (Jeschke 556 et al., 2012; Levine et al., 2004). For further developments of local competition models in a 557 community context, we advocate to develop approaches that include tolerance strategies. In the 
558 frequently used ZOI approach this could be realized by an asymmetry index that is sensitive to the

559 identity of interaction partners.

560

561 Conclusions

562 We conclude that traits related to competitive strength of species can change the effectiveness of

563 biotic resistance from resident competitors and should be taken into account when attempting to 564 predict establishment success of range expanding species. Where the impact of herbivores is of 565 minor importance, strong defence traits do not result in an apparent advantage as compared to 566 weak defence. However, herbivory might have a stabilizing effect on competition and thus should 567 not be neglected when analysing range expansion dynamics. This model may serve as a basis for 568 future large-scale models, where dispersal should be considered as a third important trait to 569 describe range expansion.

\section{References}

572 Agrawal, A.A., Fishbein, M., 2006. Plant defense syndromes. Ecology 87, S132-S149. 573 https://doi.org/10.1890/0012-9658(2006)87[132:PDS]2.0.CO;2

574 Aikio, S., 2004. Competitive asymmetry, foraging area size and coexistence of annuals. Oikos 575 104, 51-58. https://doi.org/10.1111/j.0030-1299.2004.12083.x

576 Alexander, J.M., Diez, J.M., Hart, S.P., Levine, J.M., 2016. When climate reshuffles competitors: 577 a call for experimental macroecology. Trends in Ecology \& Evolution 31, 831-841.

578 Bais, H.P., Vepachedu, R., Gilroy, S., Callaway, R.M., Vivanco, J.M., 2003. Allelopathy and 579 Exotic Plant Invasion: From Molecules and Genes to Species Interactions. Science 301, 1377580 1380. https://doi.org/10.1126/science. 1083245

581 Bakkenes, M., Alkemade, J.R.M., Ihle, F., Leemans, R., Latour, J.B., 2002. Assessing effects of 582 forecasted climate change on the diversity and distribution of European higher plants for 2050. 583 Global Change Biology 8, 390-407. https://doi.org/10.1046/j.1354-1013.2001.00467.x 
584 Bauer, J.T., 2012. Invasive species: "back-seat drivers” of ecosystem change? Biological Invasions 585 1-10.

586 Berger, U., Piou, C., Schiffers, K., Grimm, V., 2008. Competition among plants: Concepts, 587 individual-based modelling approaches, and a proposal for a future research strategy. Perspectives 588 in Plant Ecology, Evolution and Systematics 9, 121-135. 589 https://doi.org/10.1016/j.ppees.2007.11.002

590 Berg, M.P., Kiers, E.T., Driessen, G., Van Der HEIJDEN, M., Kooi, B.W., Kuenen, F., Liefting, 591 M., Verhoef, H.A., Ellers, J., 2010. Adapt or disperse: understanding species persistence in a 592 changing world. Global Change Biology 16, 587-598. https://doi.org/10.1111/j.1365$593 \quad 2486.2009 .02014 . x$

594 Brown, J.H., 1984. On the Relationship between Abundance and Distribution of Species. The 595 American Naturalist 124, 255-279. https://doi.org/10.1086/284267

596 Brown, J.H., Gillooly, J.F., Allen, A.P., Savage, V.M., West, G.B., 2004. Toward a Metabolic 597 Theory of Ecology. Ecology 85, 1771-1789. https://doi.org/10.1890/03-9000

598 CABI, 2013. Plantwise Knowledge Bank [WWW Document]. Plantwise Knowledge Bank. URL 599 http://www.plantwise.org/KnowledgeBank/home.aspx (accessed 4.15.14).

600 Cappuccino, N., Carpenter, D., 2005. Invasive exotic plants suffer less herbivory than non-invasive 601 exotic plants. Biol. Lett. 1, 435-438. https://doi.org/10.1098/rsbl.2005.0341

602 Chen, I.-C., Hill, J.K., Ohlemüller, R., Roy, D.B., Thomas, C.D., 2011. Rapid Range Shifts of 603 Species Associated with High Levels of Climate Warming. Science 333, 1024-1026. 604 https://doi.org/10.1126/science. 1206432

605 Colbach, N., Sache, I., 2001. Blackgrass (Alopecurus myosuroides Huds.) seed dispersal from a 606 single plant and its consequences on weed infestation. Ecological Modelling 139, 201-219. 607 https://doi.org/10.1016/S0304-3800(01)00236-8

608 Connolly, J., Wayne, P., 1996. Asymmetric competition between plant species. Oecologia 108, 609 311-320. 
610 Corbin, J.D., D'Antonio, C.M., 2004. Competition between native perennial and exotic annual 611 grasses: implications for an historical invasion. Ecology 85, 1273-1283. 612 https://doi.org/10.1890/02-0744

613 Damgaard, C., Weiner, J., 2008. Modeling the growth of individuals in crowded plant populations. 614 J. Plant Ecol. 1, 111-116. https://doi.org/10.1093/jpe/rtn008

615 Domingos, P., 1999. The Role of Occam's Razor in Knowledge Discovery. Data Mining and 616 Knowledge Discovery 3, 409-425. https://doi.org/10.1023/A:1009868929893

617 Edwards, G.R., Crawley, M.J., 1999. Herbivores, seed banks and seedling recruitment in mesic 618 grassland. Journal of Ecology 87, 423-435. https://doi.org/10.1046/j.1365-2745.1999.00363.x

619 Ehlers, B.K., 2011. Soil Microorganisms Alleviate the Allelochemical Effects of a Thyme 620 Monoterpene on the Performance of an Associated Grass Species. PLoS ONE 6, e26321. 621 https://doi.org/10.1371/journal.pone.0026321

622 Engelkes, T., Morrien, E., Verhoeven, K.J.F., Bezemer, T.M., Biere, A., Harvey, J.A., McIntyre, 623 L.M., Tamis, W.L.M., van der Putten, W.H., 2008. Successful range-expanding plants experience 624 less above-ground and below-ground enemy impact. Nature 456, 946-948. 625 https://doi.org/10.1038/nature07474

626 Fagan, W.F., Lewis, M., Neubert, M.G., Aumann, C., Apple, J.L., Bishop, J.G., 2005. When Can 627 Herbivores Slow or Reverse the Spread of an Invading Plant? A Test Case from Mount St. Helens. 628 The American Naturalist 166, 669-685. https://doi.org/10.1086/497621

629 Fox, L.R., Ribeiro, S.P., Brown, V.K., Masters, G.J., Clarke, I.P., 1999. Direct and indirect effects 630 of climate change on St John's wort, Hypericum perforatum L. (Hypericaceae). Oecologia 120, 631 113-122. https://doi.org/10.1007/s004420050839

632 Goldberg, D.E., 1996. Competitive ability: Definitions, contingency and correlated traits. Philos. 633 Trans. R. Soc. Lond. Ser. B-Biol. Sci. 351, 1377-1385. https://doi.org/10.1098/rstb.1996.0121

634 Grimm, V., Berger, U., Bastiansen, F., Eliassen, S., Ginot, V., Giske, J., Goss-Custard, J., Grand, 635 T., Heinz, S.K., Huse, G., Huth, A., Jepsen, J.U., Jørgensen, C., Mooij, W.M., Müller, B., Pe'er, 636 G., Piou, C., Railsback, S.F., Robbins, A.M., Robbins, M.M., Rossmanith, E., Rüger, N., Strand, 
637 E., Souissi, S., Stillman, R.A., Vabø, R., Visser, U., DeAngelis, D.L., 2006. A standard protocol 638 for describing individual-based and agent-based models. Ecological Modelling 198, 115-126. 639 https://doi.org/10.1016/j.ecolmodel.2006.04.023

640 Grimm, V., Berger, U., DeAngelis, D.L., Polhill, J.G., Giske, J., Railsback, S.F., 2010. The ODD 641 protocol: A review and first update. Ecological Modelling 221, 2760-2768. 642 https://doi.org/10.1016/j.ecolmodel.2010.08.019

643 Grimm, V., Railsback, S.F., 2005. Individual-based Modeling And Ecology. Princeton University 644 Press.

645 Guisan, A., Thuiller, W., 2005. Predicting species distribution: offering more than simple habitat 646 models. Ecology letters 8, 993-1009.

647 Harvey, J.A., Biere, A., Fortuna, T., Vet, L.E.M., Engelkes, T., Morriën, E., Gols, R., Verhoeven, 648 K., Vogel, H., Macel, M., Heidel-Fischer, H.M., Schramm, K., Putten, W.H. van der, 2010. 649 Ecological fits, mis-fits and lotteries involving insect herbivores on the invasive plant, Bunias 650 orientalis. Biol Invasions 12, 3045-3059. https://doi.org/10.1007/s10530-010-9696-9

651 Heard, M.J., Sax, D.F., 2013. Coexistence between native and exotic species is facilitated by 652 asymmetries in competitive ability and susceptibility to herbivores. Ecology Letters 16, 206-213. 653 https://doi.org/10.1111/ele.12030

654 Herrero, A., Almaraz, P., Zamora, R., Castro, J., Hódar, J.A., 2016. From the individual to the 655 landscape and back: time-varying effects of climate and herbivory on tree sapling growth at 656 distribution limits. J Ecol 104, 430-442. https://doi.org/10.1111/1365-2745.12527

657 Huang, W., Carrillo, J., Ding, J., Siemann, E., 2012. Interactive effects of herbivory and 658 competition intensity determine invasive plant performance. Oecologia 170, 373-382. 659 https://doi.org/10.1007/s00442-012-2328-6

660 Hunt, R., 1982. Plant growth curves: the functional approach to plant growth analysis. Arnold, 661 London. 
662 Janeček, Š., Patáčová, E., Klimešová, J., 2014. Effects of Fertilization and Competition on Plant 663 Biomass Allocation and Internal Resources: Does Plantago lanceolata Follow the Rules of 664 Economic Theory? Folia Geobot 49, 49-64. https://doi.org/10.1007/s12224-013-9161-5

665 Jeschke, J., Gómez Aparicio, L., Haider, S., Heger, T., Lortie, C., Pyšek, P., Strayer, D., 2012. 666 Support for major hypotheses in invasion biology is uneven and declining. NeoBiota 14, 1-20. 667 https://doi.org/10.3897/neobiota.14.3435

668 Joshi, J., Vrieling, K., 2005. The enemy release and EICA hypothesis revisited: incorporating the 669 fundamental difference between specialist and generalist herbivores. Ecology Letters 8, 704-714.

670 Keane, R.M., Crawley, M.J., 2002. Exotic plant invasions and the enemy release hypothesis. 671 Trends in Ecology \& Evolution 17, 164-170.

672 Kempel, A., Chrobock, T., Fischer, M., Rohr, R.P., Kleunen, M. van, 2013. Determinants of plant 673 establishment success in a multispecies introduction experiment with native and alien species. 674 PNAS 110, 12727-12732. https://doi.org/10.1073/pnas.1300481110

675 Kim, T.N., Underwood, N., Inouye, B.D., 2013. Insect herbivores change the outcome of plant 676 competition through both inter- and intraspecific processes. Ecology 94, 1753-1763. 677 https://doi.org/10.1890/12-1261.1

678 Kolar, C.S., Lodge, D.M., 2001. Progress in invasion biology: predicting invaders. Trends in 679 Ecology \& Evolution 16, 199-204.

680 Kuijper, D.P.J., Nijhoff, D.J., Bakker, J.P., 2004. Herbivory and competition slow down invasion 681 of a tall grass along a productivity gradient. Oecologia 141. https://doi.org/10.1007/s00442-004682 1664-6

683 Lakeman-Fraser, P., Ewers, R.M., 2013. Enemy release promotes range expansion in a host plant. 684 Oecologia 172, 1203-1212. https://doi.org/10.1007/s00442-012-2555-X

685 Larson, D.L., Anderson, P.J., Newton, W., 2001. Alien plant invasion in mixed-grass prairie: 686 effects of vegetation type and anthropogenic disturbance. Ecological Applications 11, 128-141. 
687 Ledergerber, S., Thommen, G.H., Baur, B., 1997. Grazing damage to plants and gastropod and 688 grasshopper densities in a $\mathrm{CO}<\mathrm{sub}>2</ \mathrm{sub}>$-enrichment experiment on calcareous grassland. 689 Acta Oecologica 18, 255-261.

690 Lenoir, J., Gégout, J.-C., Guisan, A., Vittoz, P., Wohlgemuth, T., Zimmermann, N.E., Dullinger, 691 S., Pauli, H., Willner, W., Svenning, J.-C., 2010. Going against the flow: potential mechanisms 692 for unexpected downslope range shifts in a warming climate. Ecography 33, 295-303. 693 https://doi.org/10.1111/j.1600-0587.2010.06279.x

694 Levine, J.M., Adler, P.B., Yelenik, S.G., 2004. A meta-analysis of biotic resistance to exotic plant 695 invasions. Ecol. Lett. 7, 975-989. https://doi.org/10.1111/j.1461-0248.2004.00657.x

696 Lin, Y., Berger, U., Grimm, V., Ji, Q.-R., 2012. Differences between symmetric and asymmetric 697 facilitation matter: exploring the interplay between modes of positive and negative plant 698 interactions. Journal of Ecology 100, 1482-1491. https://doi.org/10.1111/j.1365699 2745.2012.02019.x

700 Lockwood, J.L., Cassey, P., Blackburn, T., 2005. The role of propagule pressure in explaining 701 species invasions. Trends in Ecology \& Evolution 20, 223-228.

702 Lu, X., Ding, J., 2012. History of exposure to herbivores increases the compensatory ability of an 703 invasive plant. Biological Invasions 649-658.

704 Macel, M., Bruinsma, M., Dijkstra, S.M., Ooijendijk, T., Niemeyer, H.M., Klinkhamer, P.G.L., 705 2005. Differences in effects of pyrrolizidine alkaloids on five generalist insect herbivore species. 706 Journal of Chemical Ecology 31, 1493-1508.

707 Maggini, R., Lehmann, A., Kéry, M., Schmid, H., Beniston, M., Jenni, L., Zbinden, N., 2011. Are 708 Swiss birds tracking climate change?: Detecting elevational shifts using response curve shapes. 709 Ecological Modelling 222, 21-32. https://doi.org/10.1016/j.ecolmodel.2010.09.010

710 Matter, S.F., Brzyski, J.R., Harrison, C.J., Hyams, S., Loo, C., Loomis, J., Lubbers, H.R., 711 Seastrum, L., Stamper, T.I., Stein, A.M., Stokes, R., Wilkerson, B.S., 2012. Invading from the 712 garden? A comparison of leaf herbivory for exotic and native plants in natural and ornamental 713 settings. Insect Science 19, 677-682. https://doi.org/10.1111/j.1744-7917.2012.01524.x 
714 Matus, G., Papp, M., Tóthmérész, B., 2005. Impact of management on vegetation dynamics and 715 seed bank formation of inland dune grassland in Hungary. Flora - Morphology, Distribution, 716 Functional Ecology of Plants 200, 296-306. https://doi.org/10.1016/j.flora.2004.12.002

717 McGill, B.J., Enquist, B.J., Weiher, E., Westoby, M., 2006. Rebuilding community ecology from 718 functional traits. Trends in Ecology \& Evolution 21, 178-185. 719 https://doi.org/10.1016/j.tree.2006.02.002

720 McKay, M.D., Beckman, R.J., Conover, W.J., 1979. Comparison of three methods for selecting 721 values of input variables in the analysis of output from a computer code. Technometrics 21, 239722245.

723 Metz, J., Nisbet, R., Geritz, S., 1992. How should we define "fitness" for general ecological 724 scenarios? Trends in Ecology \& Evolution 7, 198-202.

725 Morriën, E., Engelkes, T., van der Putten, W.H., 2011. Additive effects of aboveground 726 polyphagous herbivores and soil feedback in native and range-expanding exotic plants. Ecology 727 92, 1344-1352. https://doi.org/10.1890/10-1937.1

728 Morris, E.C., 2003. How does fertility of the substrate affect intraspecific competition? Evidence 729 and synthesis from self-thinning. Ecological Research 18, 287-305. 730 https://doi.org/10.1046/j.1440-1703.2003.00555.x

731 Nehrbass, N., Winkler, E., Müllerová, J., Pergl, J., Pylvsek, P., Perglová, I., 2007. A simulation 732 model of plant invasion: long-distance dispersal determines the pattern of spread. Biological 733 Invasions 9, 383-395.

734 Olff, H., Ritchie, M.E., 1998. Effects of herbivores on grassland plant diversity. Trends in ecology 735 \& evolution 13, 261-265.

736 Paradis, E., Baillie, S.R., Sutherland, W.J., 2002. Modeling large-scale dispersal distances. 737 Ecological Modelling 151, 279-292. https://doi.org/10.1016/S0304-3800(01)00487-2

738 Parmesan, C., Yohe, G., 2003. A globally coherent fingerprint of climate change impacts across 739 natural systems. Nature 421, 37-42. 
740 Pearson, R.G., Dawson, T.P., 2003. Predicting the impacts of climate change on the distribution

741 of species: are bioclimate envelope models useful? Global Ecology and Biogeography 12, 361-

742 371. https://doi.org/10.1046/j.1466-822X.2003.00042.x

743 Radny, J., van der Putten, W.H., Tielbörger, K., Meyer, K.M., n.d. Influence of seed size on 744 performance of non-native annual plant species in a novel community at two planting densities.

745 Acta Oecologica. https://doi.org/10.1016/j.actao.2018.05.005

746 R Development Core Team, 2017. R: A Language and Environment for Statistical Computing. R

747 Foundation for Statistical Computing, Vienna, Austria.

748 Roscher, C., Schumacher, J., Baade, J., Wilcke, W., Gleixner, G., Weisser, W.W., Schmid, B., 749 Schulze, E.-D., 2004. The role of biodiversity for element cycling and trophic interactions: an 750 experimental approach in a grassland community. Basic and Applied Ecology 5, 107-121. 751 https://doi.org/10.1078/1439-1791-00216

752 Roux, P.C. le, Virtanen, R., Heikkinen, R.K., Luoto, M., 2012. Biotic interactions affect the 753 elevational ranges of high-latitude plant species. Ecography 35, 1048-1056. 754 https://doi.org/10.1111/j.1600-0587.2012.07534.x

755 Schmitt, J., Niles, J., Wulff, R.D., 1992. Norms of Reaction of Seed Traits to Maternal 756 Environments in Plantago lanceolata. The American Naturalist 139, 451-466.

757 Schmitz, O.J., 2000. Combining field experiments and individual-based modeling to identify the 758 dynamically relevant organizational scale in a field system. Oikos 89, 471-484. 759 https://doi.org/10.1034/j.1600-0706.2000.890306.x

760 Schmitz, O.J., Booth, G., 1997. Modelling food web complexity: The consequences of individual761 based, spatially explicit behavioural ecology on trophic interactions. Evolutionary Ecology 11, 762 379-398. https://doi.org/10.1023/A:1018476606256

763 Schwinning, S., Weiner, J., 1998. Mechanisms determining the degree of size asymmetry in 764 competition among plants. Oecologia 113, 447-455. https://doi.org/10.1007/s004420050397 
765 Simberloff, D., 2009. The Role of Propagule Pressure in Biological Invasions. Annual Review of

766 Ecology, Evolution, and $\quad$ Systematics 102.

767 https://doi.org/10.1146/annurev.ecolsys.110308.120304

768 Simpson, S.J., Abisgold, J.D., 1985. Compensation by locusts for changes in dietary nutrients:

769 behavioural mechanisms. Physiological Entomology 10, 443-452. https://doi.org/10.1111/j.1365-

$770 \quad 3032.1985 . t b 00066 . x$

771 Speek, T.A.A., Lotz, L.A.P., Ozinga, W.A., Tamis, W.L.M., Schaminée, J.H.J., van der Putten, 772 W.H., 2011. Factors relating to regional and local success of exotic plant species in their new 773 range. Diversity and Distributions 17, 542-551. https://doi.org/10.1111/j.1472$774 \quad 4642.2011 .00759 . x$

775 Stanton-Geddes, J., Tiffin, P.L., Shaw, R.G., 2012. Role of climate and competitors in limiting 776 fitness across range edges of an annual plant. Ecology 93, 1604-1613.

777 Strauss, S.Y., Agrawal, A.A., 1999. The ecology and evolution of plant tolerance to herbivory. 778 Trends in Ecology \& Evolution 14, 179-185. https://doi.org/10.1016/S0169-5347(98)01576-6

779 Stukonis, V., Slepetys, J., 2013. The Assessment of Agrostis Capillaris Wild Populations for Use 780 in Turf Grass Breeding. prolas 67, 277-280. https://doi.org/10.2478/prolas-2013-0049

781 Vilà, M., Gómez, A., Maron, J.L., 2003. Are alien plants more competitive than their native 782 conspecifics? A test using Hypericum perforatum L. Oecologia 137, 211-215. 783 https://doi.org/10.1007/s00442-003-1342-0

784 Vilà, M., Weiner, J., 2004. Are invasive plant species better competitors than native plant species? 785 - evidence from pair-wise experiments. Oikos 105, 229-238. https://doi.org/10.1111/j.0030$786 \quad 1299.2004 .12682 . x$

787 Walther, G.R., Post, E., Convey, P., Menzel, A., Parmesan, C., Beebee, T.J.C., Fromentin, J.M., 788 Hoegh-Guldberg, O., Bairlein, F., 2002. Ecological responses to recent climate change. Nature 789 416, 389-395. 
790 Weiner, J., Damgaard, C., 2006. Size-asymmetric competition and size-asymmetric growth in a 791 spatially explicit zone-of-influence model of plant competition. Ecol. Res. 21, 707-712. 792 https://doi.org/10.1007/s11284-006-0178-6

793 Weiner, J., Stoll, P., Muller-Landau, H., Jasentuliyana, A., 2001. The Effects of Density, Spatial 794 Pattern, and Competitive Symmetry on Size Variation in Simulated Plant Populations. The 795 American Naturalist 158, 438-450. https://doi.org/10.1086/321988

796 Wisz, M.S., Pottier, J., Kissling, W.D., Pellissier, L., Lenoir, J., Damgaard, C.F., Dormann, C.F., 797 Forchhammer, M.C., Grytnes, J.-A., Guisan, A., Heikkinen, R.K., Høye, T.T., Kühn, I., Luoto, 798 M., Maiorano, L., Nilsson, M.-C., Normand, S., Ockinger, E., Schmidt, N.M., Termansen, M., 799 Timmermann, A., Wardle, D.A., Aastrup, P., Svenning, J.-C., 2013. The role of biotic interactions 800 in shaping distributions and realised assemblages of species: implications for species distribution 801 modelling. Biological reviews of the Cambridge Philosophical Society 88, 15-30. 802 https://doi.org/10.1111/j.1469-185X.2012.00235.x

803 Zenni, R.D., Nunez, M.A., 2013. The elephant in the room: the role of failed invasions in 804 understanding invasion biology. Oikos 122, 801-815. https://doi.org/10.1111/j.1600$805 \quad 0706.2012 .00254 . x$ 


\section{Figure 1}

Overview of the scale-dependent relationship between range shift and local establishment of plants.

Range shift occurs on a large scale and at species level (a). This movement can be disaggregated into successful establishment events of local satellite populations beyond the native range border (red dots, b). Local persistence depends on the fitness of individuals in this local population. This is influenced by direct interactions, e.g. with neighbouring competitors (plant symbols) or resident herbivores (not shown), on this local scale (c). 


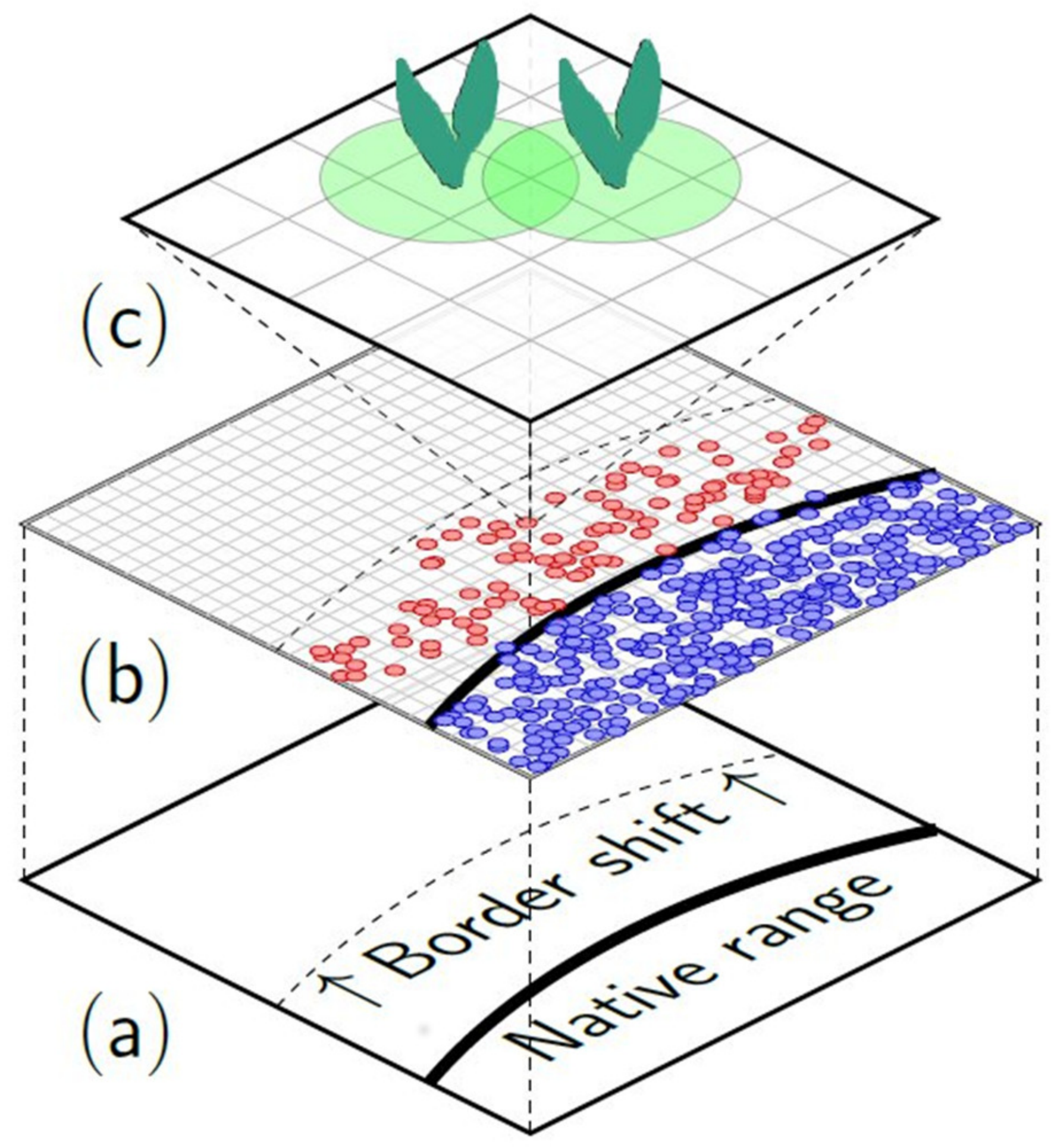


Figure 2

Order of executed routines during each simulation.

Green-coloured routines are executed only once, orange-coloured routines are executed on a "daily" basis, i.e. at each time step. Herbivory and Competition can lead to individual death of plants. 


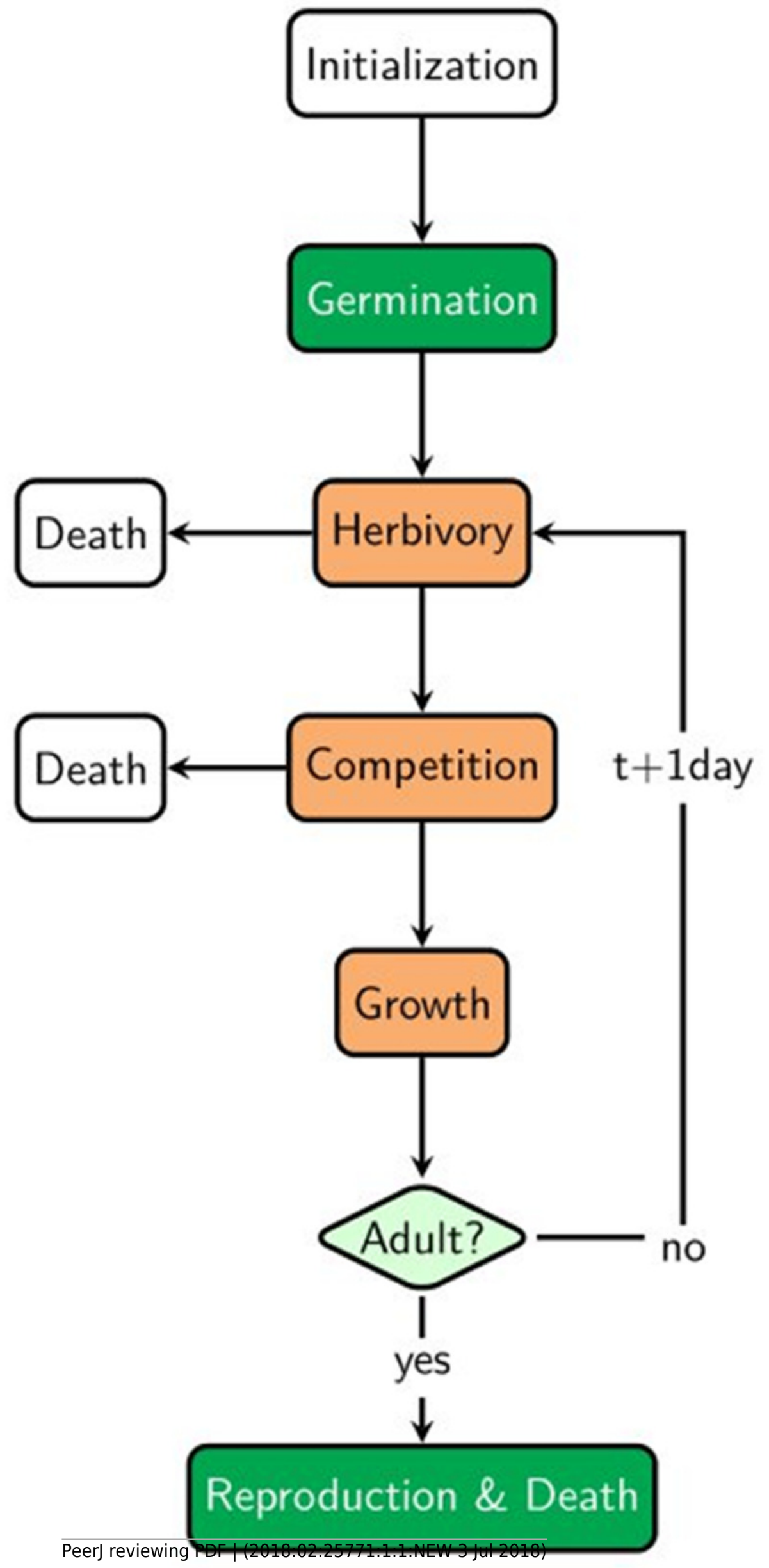




\section{Figure 3}

Screenshot of model communities after 14 days.

Model community is shown at varying initial community density (low: 308 plants, high: 1108

plants) and varying mixtures of the native community (even: same initial density of all species; literature based: species initial densities differ based on reported seed bank sizes and germination rates). Species are color-coded: Red $=$ non-native species, all other colors: native species, i.e. yellow $=A$. capilaris, green $=F$. rubra, purple $=H$. perforatum, blue $=P$. lanceolata. 

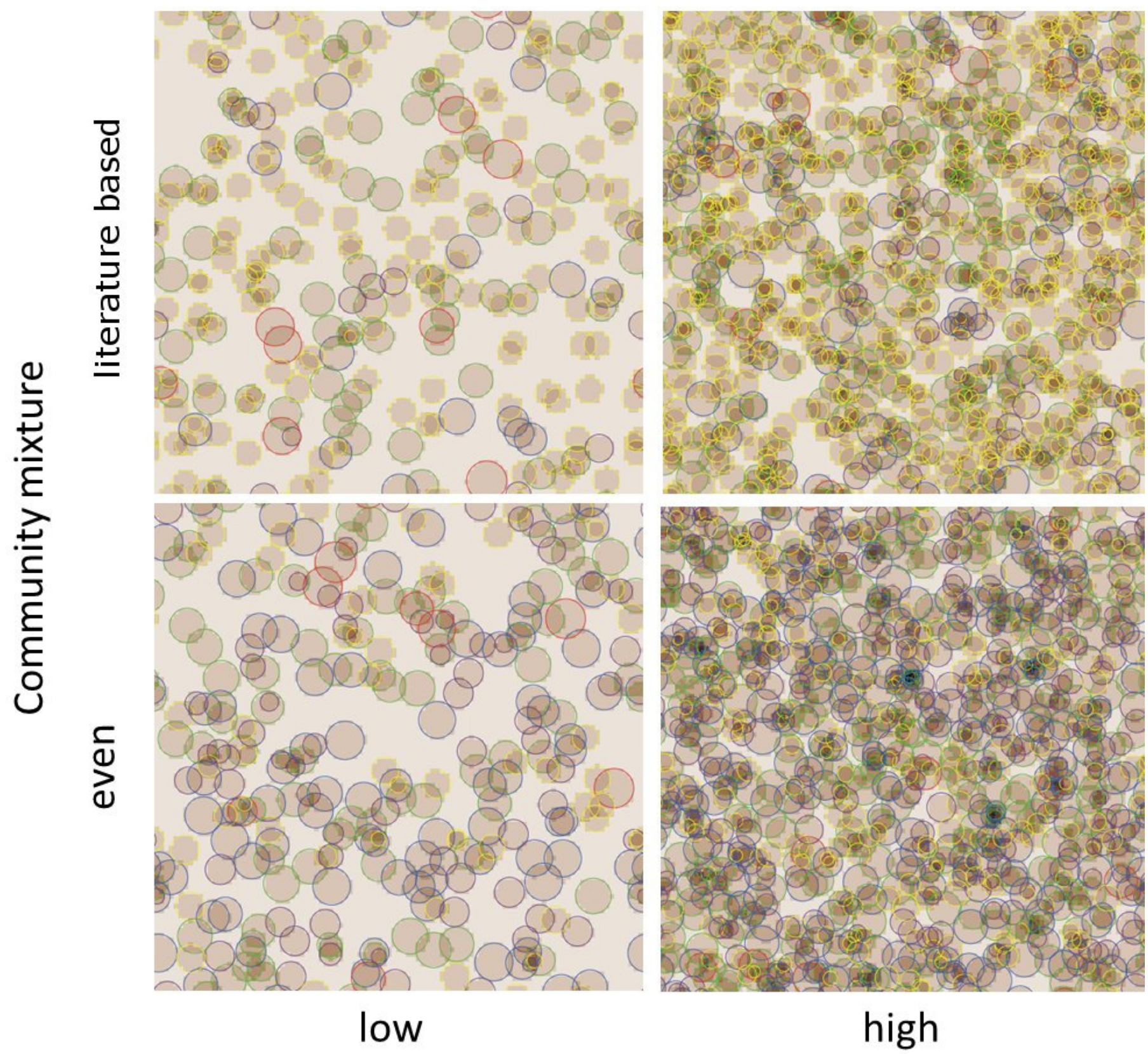

\section{high}

\section{Density}


Figure 4

Survival rates of non-native plants with different trait profiles.

The trait profiles are: high competitive and high defensive (HiAll), high competitive and low defensive (HiComp), low competitive and high defensive (HiDef), and low competitive and low defensive (LowAll). Values were averaged over all scenarios.

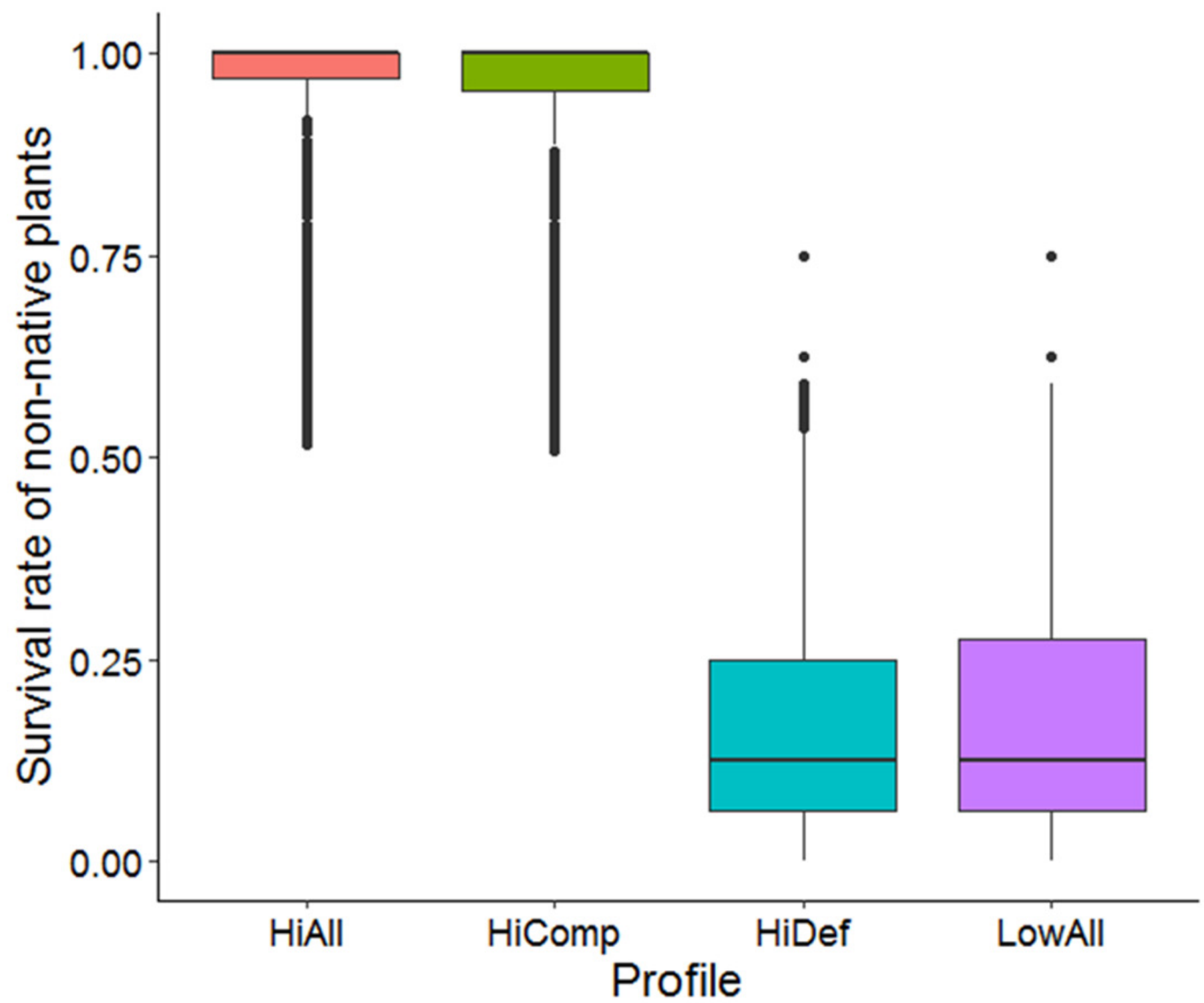




\section{Figure 5}

Survival rates of non-native plants under different invasion levels in high density (A) and low density (B) native communities.

Invasion level corresponds to initial population sizes of $8,16,32,64,128$ and 256 individuals of the non-native species. Non-natives are split into the following trait profiles (in each block from left to right): high competitive and high defensive (HiAll, orange), high competitive and low defensive (HiComp, green), low competitive and high defensive (HiDef, blue), and low competitive and low defensive (LowAll, purple).

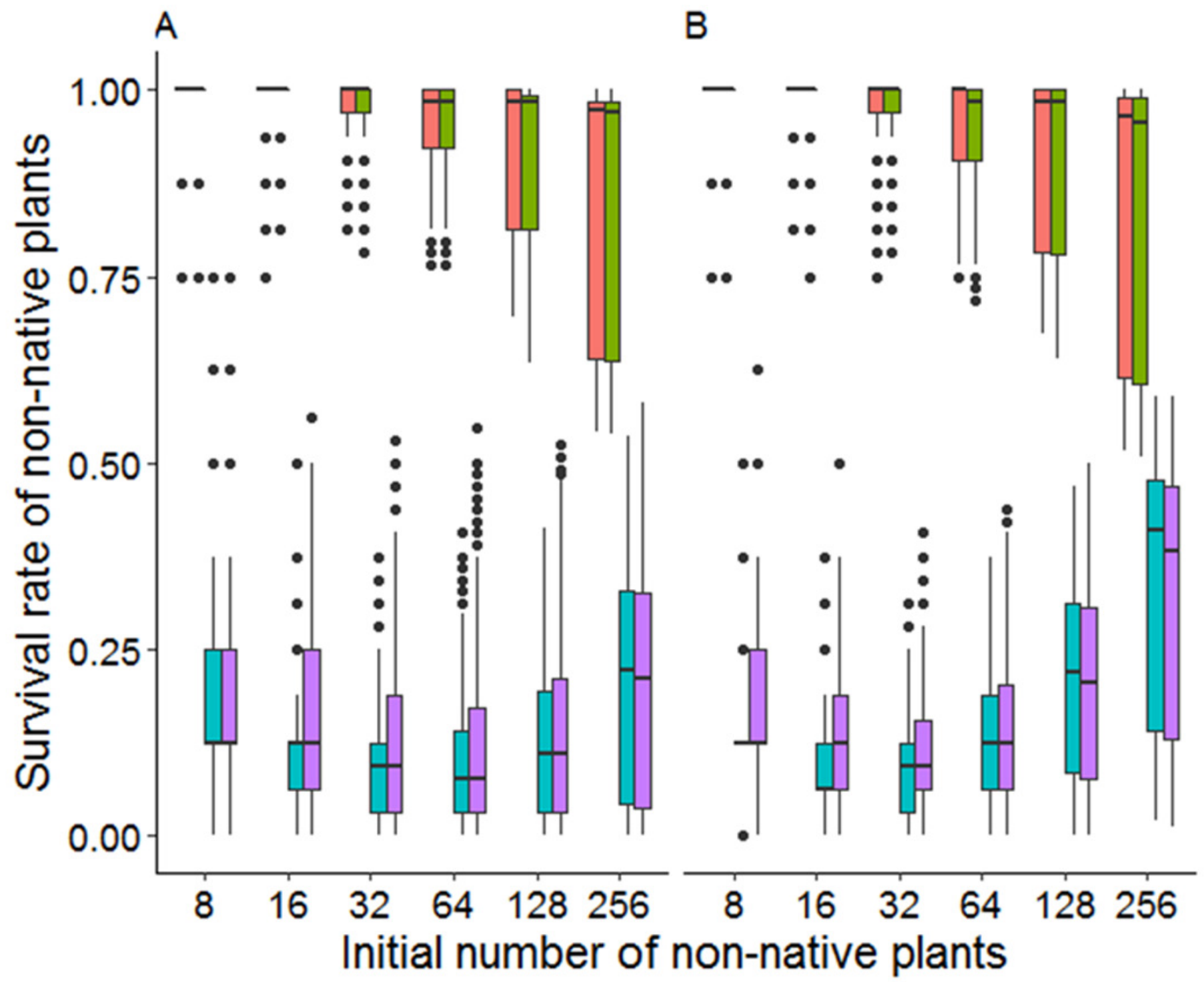




\section{Figure 6}

Effect of the intensity of competition $\Theta$ on survival rates of non-native plants in different configurations of the resident community.

Left panels ( $A, C)$ show high density of natives, right panels $(B, D)$ show low density of natives. Note that different initial numbers of non-natives are not separated in this figure. Upper panels (A, B) show an even mixture of natives in the initial community, the lower panels (C, D) show a mixture based on literature values of seed bank sizes. With $\Theta=0$, resources are shared among competitors regardless of their biomass, with $\Theta=1$, resources are shared proportionally to the biomass of the individual competitors. $\Theta=0.5$ reflects an intermediate stage. Non-natives are split into the following trait profiles (in each block from left to right): high competitive and high defensive (HiAll, orange), high competitive and low defensive (HiComp, green), low competitive and high defensive (HiDef, blue), and low competitive and low defensive (LowAll, purple). 

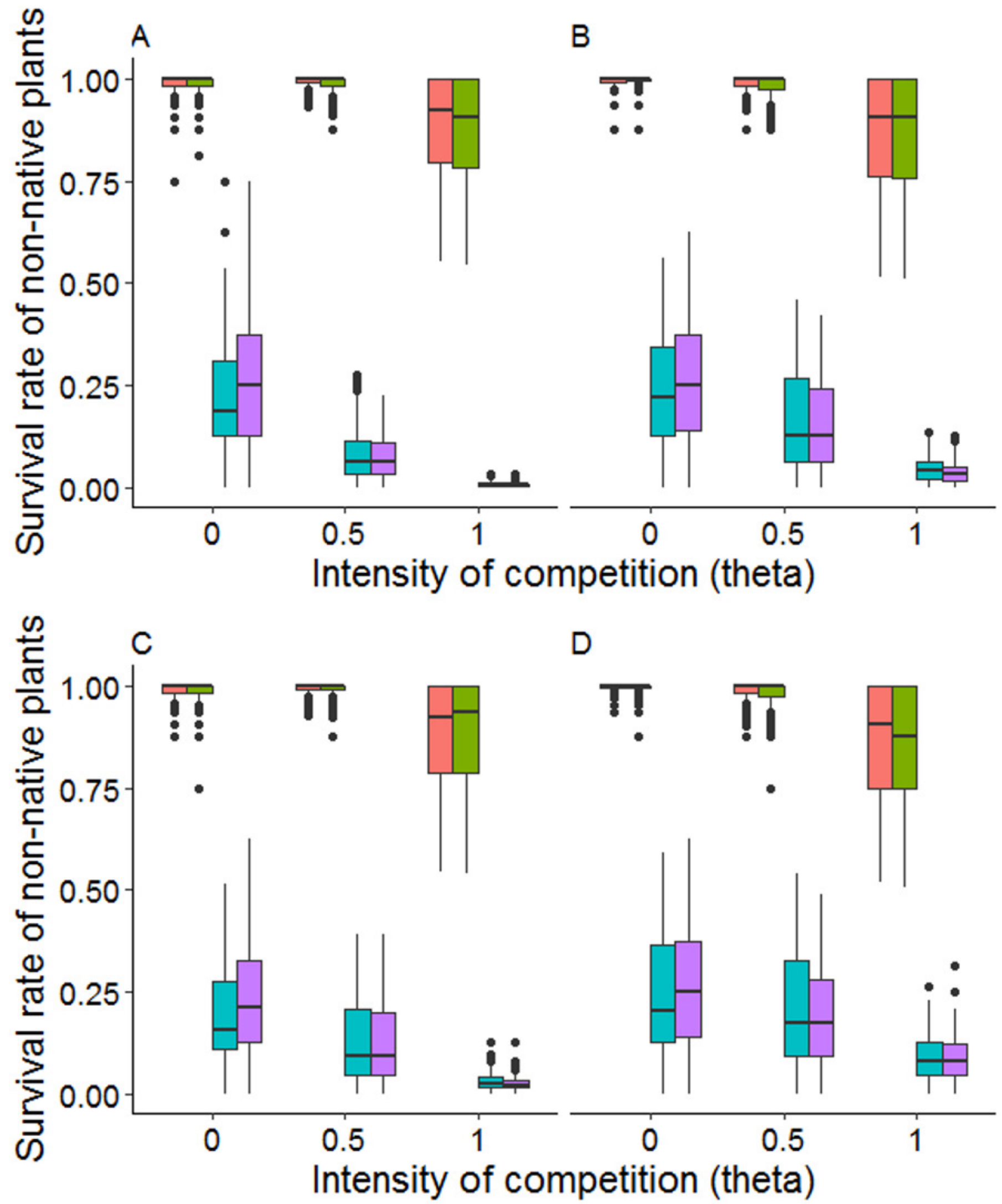
Figure 7

Survival rate of non-native species at different herbivore densities.

Herbivore densities: no herbivores as control scenario (white bars), 3.2 herbivores per $\mathrm{m}^{2}$ (light grey bars), and 18.75 herbivores per $\mathrm{m}^{2}$ (dark grey bars). Non-natives are split into the following trait profiles: high competitive and high defensive (HiAll), high competitive and low defensive (HiComp), low competitive and high defensive (HiDef), and low competitive and low defensive (LowAll).

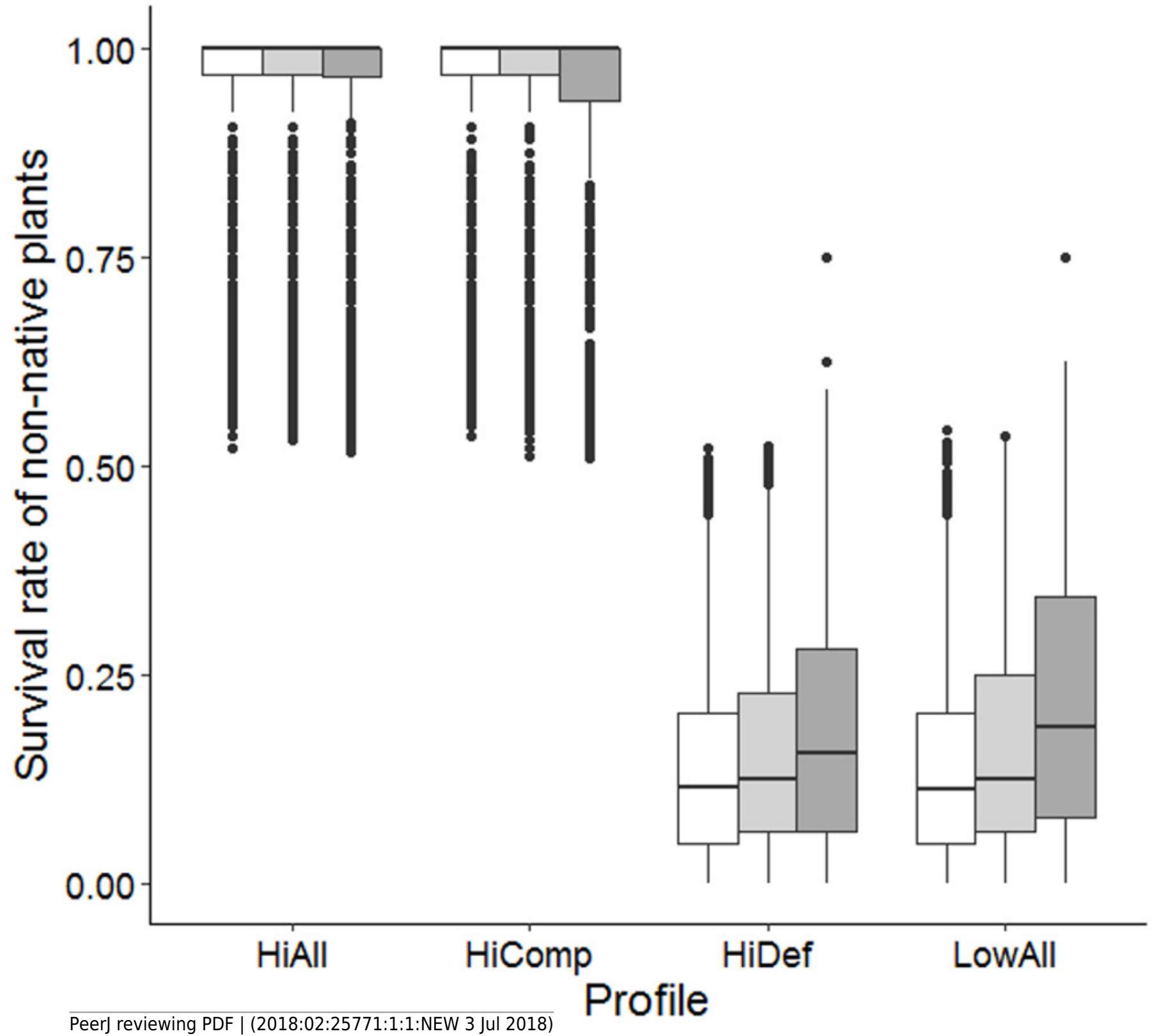




\section{Figure 8}

Standardized sensitivities of model output to model parameters.

Standardized sensitivities were a result of a generalized linear model of simulation results after statistical model simplification. Simulations were conducted with two species each, which corresponded to "native" and "non-native" species in the scenario analysis, but whose trait profiles were assembled here independent of real species (trait names ending with " 1 " or "2"). Model output was survival of species 2. Model parameters covered biotic pressures, traits (names starting with " $\mathrm{t}$ "), and their interactions. Biotic pressures included competition index (Theta), community density (DensComm), initial number of "non-natives" (InitNN), and density of herbivores (DensHerb). Traits included seed weight (tSeedWeight), maximum biomass (tMaxBiomass), germination probability (tGermProb), and repulsion of herbivores (tRepuls). 


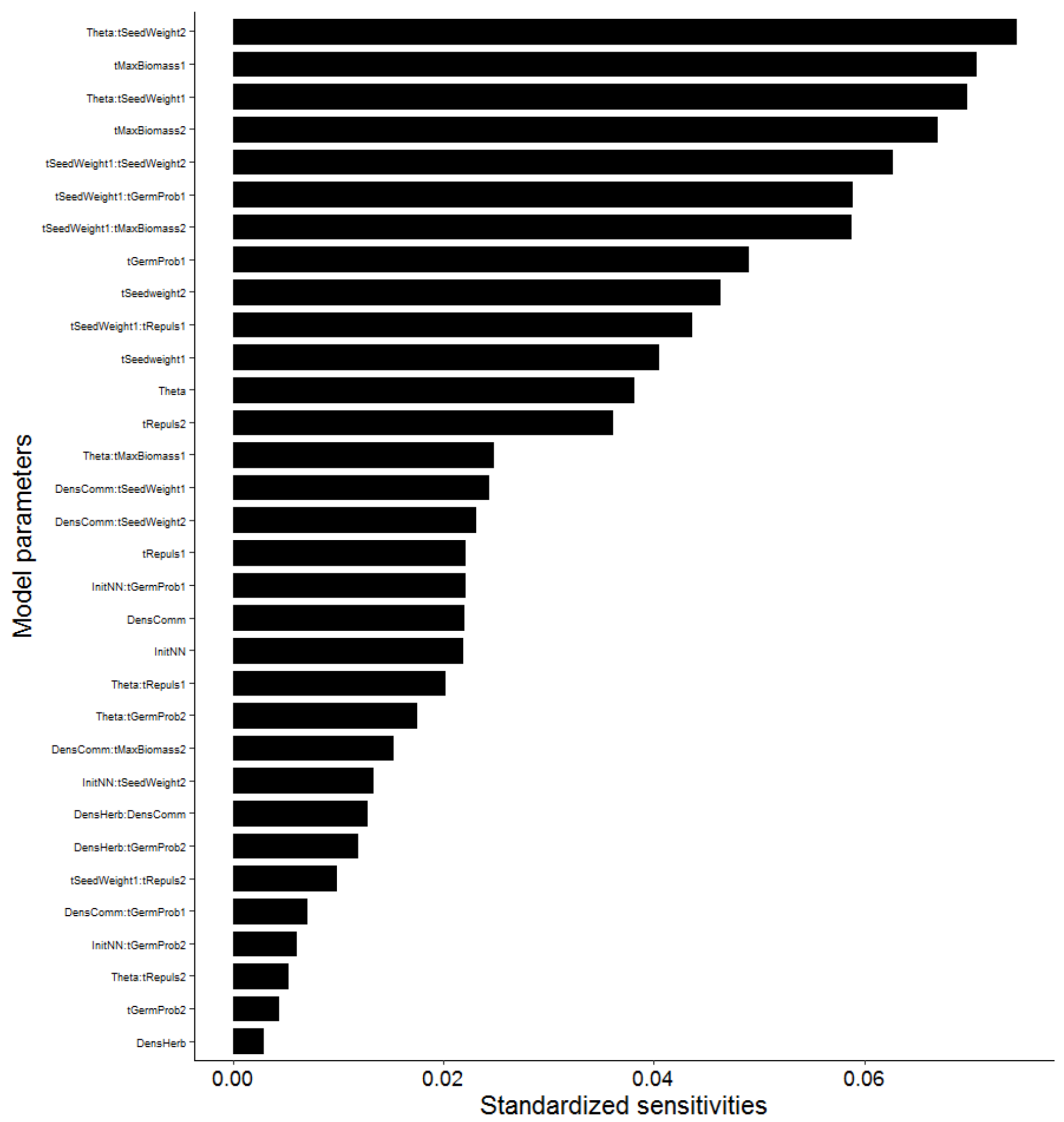




\section{Table $\mathbf{1}$ (on next page)}

Parameter values for traits of non-native plants.

Seed weight was directly measured and averaged from plant material used in the preceding experiment (Radny et al. in press) and based on the species S. capensis and B. fasciculatus. We chose maximum biomass relative to the native community. Repulsion of herbivores was averaged over all strongly and weakly defended species in the preceding experiment respectively. 


\begin{tabular}{llrll}
\hline Parameter & Unit & \multicolumn{2}{l}{ Value } & \multicolumn{2}{l}{ Source } \\
\hline Competitive strength values & Strong competitors & Weak competitors \\
Seed weight & $\mathrm{mg}$ & 3 & 1 & Radny et al. (in press) \\
Maximum biomass & $\mathrm{mg}$ & 15000 & 4000 & \\
Defensive strength values & Strong defenders & Weak defenders \\
Repulsion of herbivores & $\%$ & 70 & 30 & Radny et al. (in press) \\
\hline
\end{tabular}

1 


\section{Table 2 (on next page)}

Parameter values and their sources for the native species in the model.

Note that maximum age is aligned for all species. Reproduction and dispersal values are not considered for native species as we were not interested in the fate of native species in this approach. Parameter values were either directly retrieved or approximated $(*)$ from the available literature. The composition of the native community in uneven mixtures is based on seed bank values. Initial seed density for $F$. rubra (**) has been approximated from vegetation cover (30\%) as retrieved from Edwards and Crawley (1999), assuming that all seeds germinate and build the entire native community. 


\begin{tabular}{|c|c|c|c|c|}
\hline Species & Parameter & Unit & Value & Source \\
\hline Plantago & Seed weight & $\mathrm{mg}$ & 1.4 & Schmitt et al. (1992)* \\
\hline \multirow[t]{5}{*}{ lanceolata } & Maximum biomass & $\mathrm{mg}$ & 8000 & Janeček et al. (2014) \\
\hline & Repulsion of & [] & 0.4 & Radny et al. (in press) \\
\hline & herbivores & & & \\
\hline & Initial seeds & 1 & 85 & Edwards and Crawley (1999)* \\
\hline & & $m^{2}$ & & \\
\hline \multirow{6}{*}{$\begin{array}{l}\text { Hypericum } \\
\text { perforatum }\end{array}$} & Seed weight & $\mathrm{mg}$ & 0.09 & Fox et al. (1999) \\
\hline & Maximum biomass & $\mathrm{mg}$ & 5800 & Vilà et al. (2003) \\
\hline & Repulsion of & [] & 0.9 & Radny et al. (in press) \\
\hline & herbivores & & & \\
\hline & Initial seeds & 1 & 98 & Matus et al. (2005) \\
\hline & & $m^{2}$ & & \\
\hline \multirow{6}{*}{$\begin{array}{l}\text { Agrostis } \\
\text { capillaris }\end{array}$} & Seed weight & $\mathrm{mg}$ & 0.06 & Stukonis and Slepetys (2013) \\
\hline & Maximum biomass & $\mathrm{mg}$ & 4000 & Ehlers (2011) \\
\hline & Repulsion of & [] & 0.3 & Radny et al. (in press) \\
\hline & herbivores & & & \\
\hline & Initial seeds & 1 & 1343 & Edwards and Crawley (1999)* \\
\hline & & $m^{2}$ & & \\
\hline \multirow{6}{*}{$\begin{array}{l}\text { Festuca } \\
\text { rubra }\end{array}$} & Seed weight & $\mathrm{mg}$ & 0.77 & Larson et al. (2001) \\
\hline & Maximum biomass & $\mathrm{mg}$ & 12000 & Corbin and D'Antonio (2004)* \\
\hline & Repulsion of & [] & 0.3 & Radny et al. (in press) \\
\hline & herbivores & & & \\
\hline & Initial seeds & 1 & 654 & Edwards and Crawley (1999)** \\
\hline & & $m^{2}$ & & \\
\hline
\end{tabular}




\section{Table 3(on next page)}

Overview of components of model scenarios.

Model scenarios were put together by choosing one level per component. All possible combinations of levels were run in our model analysis. 


\begin{tabular}{lcl}
\hline $\begin{array}{l}\text { Component of model } \\
\text { scenario }\end{array}$ & $\begin{array}{c}\text { Number of } \\
\text { levels }\end{array}$ & Levels \\
\hline Trait profiles & 4 & $\begin{array}{l}\text { high competitive and high defensive (HiAll), } \\
\text { high competitive and low defensive (HiComp), } \\
\text { low competitive and high defensive (HiDef), } \\
\text { low competitive and low defensive (LowAll) }\end{array}$ \\
\hline $\begin{array}{l}\text { Initial population size } \\
\text { of non-natives }\end{array}$ & 6 & $8,16,32,64,128,256$ \\
$\begin{array}{l}\text { Competition intensity } \\
\text { or asymmetry (theta) }\end{array}$ & 3 & $0,0.5,1$ \\
\hline Community density & 2 & $\begin{array}{l}300 \text { plants (low), } \\
1100 \text { plants (high) }\end{array}$ \\
\hline $\begin{array}{l}\text { Mixture of the native } \\
\text { community }\end{array}$ & 2 & $\begin{array}{l}\text { same initial density of all species (even), } \\
\text { species initial densities differ based on reported } \\
\text { seed bank sizes and germination rates (literature } \\
\text { based) }\end{array}$ \\
\hline Herbivore density & 3 & $\begin{array}{l}\text { no herbivores (control), } \\
3.2 \text { herbivores per } \mathrm{m}^{2} \text { (low), } \\
18.75 \text { herbivores per } \mathrm{m}^{2} \text { (high) }\end{array}$ \\
& &
\end{tabular}

1 


\section{Table 4 (on next page)}

Effects of traits and community configuration on survival of non-native species.

Effects of trait values (competitive and defensive ability) and community configuration (herbivore density, community density and mixture, intensity of competition and initial number of non-natives) on survival of non-native species in a generalized linear model with quasibinomial errors presented as estimates of the effects and their corresponding standard errors, $t$-values and $p$-values. The Intercept corresponds to low competitive ability, low defensive ability, high community density and even community mixture. Asterisks indicate $p$ values smaller than $0.01(* *)$ or $0.001(* *)$. 


\begin{tabular}{|c|c|c|c|c|c|}
\hline & Estimate & $\begin{array}{l}\text { Std. } \\
\text { Error }\end{array}$ & $t$-value & $p$-value & \\
\hline Intercept & -2.43 & 0.020 & -118.68 & $<0.001$ & $* * *$ \\
\hline High competitive ability (Comp) & 10.38 & 0.033 & 312.34 & $<0.001$ & $* * *$ \\
\hline High defensive ability (Def) & -0.22 & 0.017 & -13.05 & $<0.001$ & $* * *$ \\
\hline Initial number of non-natives (InitNN) & 0.006 & 0.000 & 75.87 & $<0.001$ & $* * *$ \\
\hline Herbivore density (DensHerb) & 0.48 & 0.010 & 46.68 & $<0.001$ & $* * *$ \\
\hline Competition intensity $\Theta$ (Theta) & -2.61 & 0.032 & -81.89 & $<0.001$ & $* * *$ \\
\hline Low community density (DensComm) & 0.53 & 0.017 & 31.77 & $<0.001$ & $* * *$ \\
\hline Uneven community mixture (Mix) & -0.005 & 0.016 & -0.34 & 0.73 & \\
\hline Comp:InitNN & -0.014 & 0.000 & -141.82 & $<0.001$ & $* * *$ \\
\hline Comp:DensHerb & -0.28 & 0.008 & -32.81 & $<0.001$ & $* * *$ \\
\hline Comp:Theta & -2.67 & 0.021 & -127.50 & $<0.001$ & $* * *$ \\
\hline Comp:DensComm & -1.20 & 0.014 & -82.55 & $<0.001$ & $* * *$ \\
\hline Comp:Mix & -0.67 & 0.014 & -47.95 & $<0.001$ & $* * *$ \\
\hline Def:InitNN & 0.0005 & 0.000 & 7.59 & $<0.001$ & $* * *$ \\
\hline Def:DensHerb & 0.023 & 0.006 & 3.89 & $<0.001$ & $* * *$ \\
\hline Def:Theta & 0.14 & 0.011 & 12.80 & $<0.001$ & $* * *$ \\
\hline Def:DensComm & 0.064 & 0.010 & 6.63 & $<0.001$ & $* * *$ \\
\hline InitNN:DensHerb & -0.0004 & 0.000 & -11.44 & $<0.001$ & $* * *$ \\
\hline InitNN:Theta & -0.001 & 0.000 & -10.09 & $<0.001$ & $* * *$ \\
\hline InitNN:DensComm & 0.0008 & 0.000 & 12.07 & $<0.001$ & $* * *$ \\
\hline InitNN:Mix & 0.0005 & 0.000 & 7.29 & $<0.001$ & $* * *$ \\
\hline DensHerb:Theta & -0.121 & 0.009 & -12.88 & $<0.001$ & $* * *$ \\
\hline DensHerb:DensComm & -0.158 & 0.006 & -26.61 & $<0.001$ & $* * *$ \\
\hline DensHerb:Mix & -0.016 & 0.006 & -2.71 & $<0.01$ & $* *$ \\
\hline Theta:DensComm & 0.544 & 0.016 & 33.49 & $<0.001$ & $* * *$ \\
\hline Theta:Mix & 0.629 & 0.016 & 40.43 & $<0.001$ & $* * *$ \\
\hline
\end{tabular}

2 